\title{
CHIAPAS: SU ARTE Y SU HISTORIA COLONIALES
}

\author{
POR \\ SALVADOR TOSCANO
}

LA CONQUISTA

D ESDE 1523 se inició la Conquista de Chiapas. La historia va unida a los nombres de Luis Marin y Diego de Mazariegos en la reducción de la alta meseta; Pedro de Alvarado en el litoral del Pacífico, y el propio Hernán Cortés en la zona selvática de la cuenca del Usumacinta.

En efecto, fué en 1523 cuando Luis Marín recibió soldados e instrucciones de Cortés para pacificar la región de Chiapas. Casi todo el territorio mexicano habia sido hollado por aquellos años, conquistándose a totonacas, mixtecas, zapotecas, tarascos, colimenses, por capitanes entre los que se contaban Pedro de Alvarado, Gonzalo de Sandoval, Francisco de Orozco, Cristóbal de Olid, etc. Vino a tocarle a Luis Marín, vie- 
jo conquistador que figuró entre los capitanes del sitio de México, 1 recibir órdenes de Hernán Cortés para salir de la villa de Coatzacoalcos, Veracruz, y pacificar a los indios no reducidos de Chiapas. Bernal Diaz describe a Luis Marín como "bueno e no era malicioso" y refiere los hechos de la primera entrada de españoles a Chiapas como testigo presencial; 2 Marin entró por Iztapa đe donde avanzó al poblado indigena de Chiapa, cabeza de los señoríos indigenas de aquella región, pues tenían sometidos a zoques, tzendales y quelenes, no estando ellos sujetos a los aztecas, cuya más cercana guarnición era la de Zinacantán. 3 Por la cuaresma de 1523, afirma Bernal Diaz, llegaron los españoles a Chiapa, cuyas defensas naturales las constituían encrespados riscos y el rio Grijalva, defensas que, dice Remesal, los habían preservado de las conquistas mexicanas. Ayudados por los indigenas de Jalcpec, que aprovecharon la ocasión para rebelarse, los conquistadores españoles dominaron a Chiapa, tras de lo cual se dieron en obediencia los de Zinacantlán, Copainahuastla, Huiztán y Chamula —esta última reducida más tarde por las armas-. Luis Marín, sin embargo, no se detuvo a consolidar sus conquistas, y al finalizar de aquel año abandonó el territorio chiapaneco para retornar a Coatzacoalcos.

La segunda entrada de los españoles en la meseta chiapaneca la realizó Diego de Mazariegos después de 1527 y fué la verdadera conquista de aquel territorio. Pero ya antes, hacia 1524, cruzaba el sur del territorio de lo que actualmente es aquel Estado, Pedro de Alvarado conquistando la estrecha faja cálida costera del Soconusco. Había salido de México el 6 de diciembre de 1523 y después de atràvesar Tehuantepec llegó a Soconusco en enero del año siguiente, en el cual los indios se dieron en obediencia, después de lo cual pasó a Guatemala por el rumbo de Quetzaltenango a la conquista del señorio de Utatlán.

Otra expedición que cruzó el Esstado hacia la región nororiental, expedición que no llegó a consolidar sus conquistas por medio de fundación

1 Manuel Orozco y Betra: Los Conquistadores de México (en el tomo IV, Pág. 415 de la Historia General de las Casas de la Nueva España, de Fray Betnardino de Sahagún). México, 1938.

2 Bernal Díaz del Castillo: Historia Verdadera de la Nueva España. Cap. CLXVI.

3 Fray Antonio de Remesal: historia General de las Indias Occidentales y particularmente de la Gobernación de Chiapas y Guatemala T. I. Cap. XIII, Pág. 328. Guatemaia, C. A., 1932. 
de poblaciones castellanas, fué la de Hernán Cortés a las Hibueras. Salió de México en octubre de 1524 y cruzó Chiapas en la región cercana a Palenque, en las cuencas del Grijalva y del Ustumacinta, en los primeros meses de 1525, siguiendo una ruta que todavia no ha sido definitivamente identificada.

Pero, como hemos indicado, el verdadero conquistador del núcieo fundamental del Estado, de la altiplanicie central, fué Diego de Mazariegos en 1527-28. A Mazariegos no se le encuentra entre los conquistadores, sino entre los primeros pobladores, ocupando puestos en el Ayuntamiento de la Ciudad de México y figurando entre los acompañantes de Cortés en la expedición a las Hibueras. Diego de Mazariegos realizó las capitulaciones con el gobernador de la Nueva España, Alonso de Estrada, su pariente, iniciando su marcha en 1527 para la conquista de Chiapas. Remesal conserva una importante nómina de los conqquistadores 4 y noticia de los hechos históricos. En realidad la defensa de aquel territorio casi se redujo a la población de Chiapa, ciudad india fundada aproximadamente a cuatro kilómetros de la Chiapa actual: los indígenas se remontaron a los riscos "hasta que no pudieron levantar los brazos y viéndose perdidos, con sus mujeres y sus hijos se despeñaron por la parte del río que es altisima..." Arrojándose al río Grijalva terminó en esta forma dramática aquel grande señorío que ni siquiera los aztecas habían podido sojuzgar.

Mazariegos fundó inmediatamente Chiapa en el sitio que hoy ocupa; pero buscando tierras más saludables y frías, se remontaron a las llanuras de Hueyzacatlán, donde fundó en marzo de 1528 Villa Real, más tarde Ciudad Real, así llamada en recuerdo de su ciudad y actualmente conocida con el nombre de San Cristóbal las Casas. Todavia tuvo Mazariegos ocasión de obligar a las gentes de Alvarado, mandadas por Pedro Portocarrero, a retirarse a Guatemala a la altura de Comitán desde donde pretendía llegar al centro de Chiapas reclamando aquellas tierras para el Adelantado Pedro de Alvarado. En 1529 Mazariegos abandonó el territorio, regresando a México a su puesto de regidor del Ayuntamiento y a instruir su juicio de residencia que le formara la primera de las Audiencias. Remesal no deja de lamentarse de la ausencia de un gobernante como Mazariegos cuya prudencia y rectitud pondera.

Algún tiempo después se realizó la conquista espiritual : lógicamente fueron franciscanos y dominicos los primeros que cruzaron aquellas te-

4 Remesal. Ob. Cit. T. I. Pig. 379. 
giones. Hacia 1525 atravesaron Chiapas, en la porción nororiental, los franciscanos flamencos que acompariaban a Cortés en su viaje a las $\mathrm{Hi}$ bueras, fray Juan de Tecto y fray Juan de Aora. En 1529 el dominico fray Domingo de Betanzos cruzó Soconusco en camino a Guatemala, donde habría de iniciar, con la fundación del convento de Santiago de Guatemala, la importante obra de evangelización que casi por entero se reservó en aquellas regiones a su orden. Existe incertidumbre sobre los compañeros de fray Domingo, pero la Isagoge afirma que fueron fray Bernardino de Minaya, fray Vicente de las Casas, fray Francisco de Sta. María o de Mayorga y fray Pedro de Santa Maria o de Angulo. 5

Sin embargo, la obra de evangelización habría de realizarse todavía algunos años después, ya que Chiapas no recibió tan tempranamente los beneficios dominicos que Guatemala. Desde 1528 Mazariegos habia llevado entre sus gentes, dice Remesal, clérigos como capellanes del ejército, a Pedro González y Pedro Castellanos, primero y segundo párrocos, respectivamente, de Ciudad Real, pero quienes más que iniciar la conversión de indios se dedicaban a la población española, no por cierto con toda la riģide $z$ deseable. El tercer párroco fué nombrado por el obispo de Tlaxcala, fray Julián Garcés, en 1835, Juan Rebollo. Asi siguió aumentando el número de clérigos tan raquíticamente que a la llegada de fray Bartolomé de las Casas, en 1545, año en que se inició definitivamente la evangelización dominica de aquella región, existian clérigos únicamente en Ciudad Real, amén de otros tres repartidos en la diócesis.

Para entonces ya existía iglesia en San Cristóbal, pues fué uno de los primeros actos de los fundadores de aquella ciudad señalar sitio para una iglesia dedicada a la Virgen y nombrada de Nuestra Señora de la Asunción; años más tarde se cambió advocación a San Cristóbal y asi la llamó Paulo III en la bula por la cual la erigió de iglesia parroquial en Catedral en 1538.

El primer obispo, don Juan de Ortega, fué elevado a esa dignidad en 1539 , pero renunció a la diócesis sin haber recibido consagración episcopal. El segundo, don Juan de Arteaga y Avendaño, fué elevado en 1541, pero habiendo salido a tomar posesión murió en la ciudad de Puebla a consecuencia de un envenenamiento accidental. El tercero vino a ser fray Bartolomé de las Casas, elevado a tal dignidad en 1543, quien llegó a

5 Isagoge. Histórica Apologética de las Indias Occidentales. Guatemala, C. A., 1935. Pág. 250. 
Chiapas en 1545 y abandonó aquel territorio poco tiempo después, sucediéndole fray Tomás Casillas.

Chiapas primeramente había formado parte de la diócesis Carolense. Esta diócesis, desprendida de la de Sevilla, se formó a raiz de la conquista y por lo mismo con límites tan vastos que abarcaba desde Yucatán hasta México. En 1526 Carlos V le fijó límites incluyendo a Chiapas. Pero erigido el obispado de Guatemala, en 1534 pasó a formar parte de aquella diócesis, hasta que por informes del propio obispo Marroquín, $y$ en vista de la extensión de su obispado, se erigió la nueva diócesis chiapaneca el 19 de marzo de 1539.

Esta diócesis formó parte, desde sus inicios hasta 1722, de la Provincia de México, y desde esta fecha hasta 1831, de la de Guatemala, fecha esta última en que la Santa Sede reconoció la independencia mexicana y en la cual se volvió nuevamente a incluir en la provincia mexicana. 6

La evangelización indígena del Estado fuẻ iniciada sistemáticamente por los mercedarios. Dice Remesal, autoridad inevitable en este capítulo, que al regresar el obispo Marroquín a Guatemala, después de ser consagrado en México en 1537, trajo frailes mercedarios por no poder disponer de franciscanos o dominicos: "Por orden suya se fundó el año pasado de 1537 el convento de Nuestra Señora de la Merced de Ciudad Real, siendo su primer comendador el P. Fr. Pedro de Barrientos". 7

Pero como señalábamos previamente, la obra de conquista espiritual de aquellas regiones quedó exclusivamente encomendada a la orden de Santo Domingo. La penuria de la orden de la Merced, confinó a ésta hasta casi anularla. Los franciscanos establecieron convento hasta 1577. 8 En 1625 en que estuvo en Ciudad Real Tomás Gage, no había sino tres conventos: dominico, franciscano y uno de monjas; no llegaban, pues, aún los jesuítas y tampoco existían conventos agustinos, quizá por la pobreza de aquella región, como lo hizo notar Gage.

6 Datos que se encuentran en el estudio impreso mimeográficamente: IV Centenario de la Fundación de la Diócesis Chiapas, 1539-1939, de los Sres. G. A. y D. B.

7 Remesal, Ob. Cit. Pág. 218. T. 1. Al mencionar al primer comendador, Pedro de Barrientos, Remesal incurte en un error, ya que este fraile fué dominico $y$ Ilegó hasta 1554: probablemente se deba leer Fray Marcos Pérez Dardón.

8 El cronista Vázquez señala el año 1575, pero según el Sr. Orozco y Jiménez, de un Ms. del antiguo convento y del propio Vázquez, se deduce que fueta en 1577. F. Orozco y Jiménez: Colectión de Documentos inéditos relativos a la Iglesia de Chiapas. San Cristóbal las Casas, 1911. T. II. Pág. 137. 
En 1544, fray Bartolomé de las Casas llevó a Chiapas los primeros dominicos que en número de 44 salieron de Salamanca conducidos por su vicario y cuarto obispo de Chiapas, fray Tomás Casillas. Pormenorizadamente traen estos hechos Remesal y Ximénez, ambos inspirados en un mantuscrito de uno de los frailes dominicos llegados en esa época, fray Tomás de la Torre, manuscrito hoy perdido del que fuera primer cronista de aquella región. E1 12 de marzo llegaron a Ciudad Real; fray Bartolomé los había precedido. Los mercedarios recibieron aquel nuevo grupo con hostilidad y, con mayor razón, el grupo de encomenderos de Chiapas, culminando en graves luchas entre el obispo y los encomenderos. Los dominicos se retiraron de Ciudad Real, regresando más tarde y dispersándose en Soconusco, Zỉnacantán, Copainguastlan, Chiapa, etc.

Pero ya para fines del siglo XVI existian dos conventos, el de Santo Domingo y el de San Francisco - pues es de notar que por su penuria apenas mencionan diversos cronistas, como el padre Ponce (1584) y fray Tomás Gage (1625), el convento de mercedarios-. Gage menciona a principios del siglo XVII, aparte de los dos ya mencionados, el de monjas, es decir, el de la Encarnación de las monjas concepcionistas y expresamente hace notar que no hay jesuítas porque éstos sólo viven en ciudades ricas. 9

La Compañía de Jesús debió entrar en Chiapas después que una vecina de aquelia ciudad, María de Alvarado, testó a la Compañia una hacienda de árboles de cacao: la resolución aprobatoria de la reina lleva fecha de 1675,10

Durante el siglo XVIII, según una Relación de la Provincia de Chiapa descubierta por el Sr. Orozco y Jiménez en la Biblioteca Víctor Manuel de Roma, que no lleva fecha ni nombre de autor, pero que debe ser posterior a 1767 -año de la expulsión de los jesuítas de América-, se mencionan aparte de la catedral, "Un convento de monjas del título de la Encarnación de $N$. Sor. y cuatro monasterios de frailes, a saber, de Dominicos, Franciscanos, Mercedarios y Hospitalarios de San Juan de Dios; y también hnvo un Colegio de la Compañía”. 11

9 Tomás Gage: Nueva Relación que contiene los viajes de Tomás Gage en la Nueva España. París, 1838. T. I. Pág. 331.

10 Orozco y Jiménez. Ob. Cit. T. II. Pág. 2.

11 Orozco y Jiménez. Ob. Cit. T. I, Pág, 18. 
Iglesia y Convento Dominico.

El convento dominicano de Chiapa es seguramente uno de los monumentos del siglo XVI de aquella región más completos, pues salvo el convento, que se encuentra en ruinas, la iglesia se preserva inmejorablemente.

Desde la llegada de los primeros dominicos en 1545 se pensó en fundar alli un convento, ya que el sitio era la cabeza de los señorios indigenas de Chiapas. Ximénez transcribe importantes noticias de un manuscrito, hoy perdido, que atribuye a fray Tomás de la Torre, quien dice que el encomendero teniales "un sitio en' lo mejor del pueblo y encima del tío (Grijalva) donde hay una fuentecilla". 12 Sin embargo, todavía en 1548 no se trabajaba en la fábrica, ya que, por cédula real de Carlos V del 17 de septiembre de ese año, se ordena que se construyan monasterios, pues "en dicha Provincia no hay monasterios hechos". 13 Remesal añade este importante dato al hablarnos de los dominicos, de quienes dice que al esparcirse en aquellos territorios "llegaron a Chiapa y señalados para aquella casa, cuya traza se estaba dando, al mismo padre fray Tomás Casillas, vicario..." 14

Remesal atribuye la obra del convento a fray Pedro de Barrientos. Este fraile dominico procedía del convento de Nuestra Señora de la Peña de Francia, y era de origen portugués; habia arribado a aquella región en 1554. 15 Ahora bien, ¿fray Pedro Barrientos había encontrado dispuesta ya la traz y la construcción antes de 1554, o bien el convento debe atribuirse integramente $y$ fecharlo como posterior a aquel año? Dice Remesal: "Año de 1588 fué nuestro Señor servido de llevar para si al padre Fray Pedro de Barrientos de nación portugués, hijo del convento de Nuestra Señora de la Peña de Francia, de quien algunas veces se ha hecho mención en esta historia, murió en el Convento de Chiapa de Indias, que él

12 Fray Francisco Ximénez: Historia de la Provincia de San Vicente de Chiapa y Guatemala. Guatemala. C. A., 1929. T. I. Pág. 351.

13 Remesal, Ob. Cit. T. II. Pág. 215.

14 Remesa1, Ob. Cir. T. I. Págs. 424-425.

15 Remesaj, Ob. Cit. T. II. Pág. 358. 
habia edificado como ahora está, y de donde había sido primer vicario y primer prior, cuando aquella casa se dividió de la Ciudad Real, y se hizo una de las de la Provincia, y según el padre Fray Pedro la ordenó y compuso, es una de las buenas que tiene la orden de la Nueva España; la iglesia es muy capaz y muy fuerte, de tres naves, de ladrillo, y la capilla mayor proporcionada y con el aderezo de los retablos que en ella pusieron los padres Fray Melchor Gómez y Fray Juan Alonso, sienđo priores, está muy vistosa. El claustro está bien edificado y las celdas son capaces y buenas; tienen las más vistas al río, por ser la tierra muy calurosa. El refitorio y hospicio y las demás oficinas están muy acomodadas, con toda la casa, y la huerta con su estanque es de mucha recreación. La Sacristía muchos y muy ricos ornamentos, y por la liberalidad de los priores quizás más caros que en otras partes". 16 Me inclino a aceptar a fray Pedro de Barrientos como su constructor, con lo cual deberemos fijar la fecha de construcción de aquella iglesia y convento entre un año inmediatamente posterior a 1554 y 1572 en que fuera aceptado como casa el convento - debe notarse que la campana mayor lieva inscrita la fecha de su fundición, 1576, fecha en que estaba ya construido-.

De la fábrica actualmente sólo la jglesia y parte del convento no se encuentran en ruinas. Aquélla está trazada en tres naves que dividen dos columnatas interiores, originando una nave central y dos laterales, al estilo basilical renacentista de los conventos de Zacatlán, Tecali y Cuilapan. Su techumbre es de artesón o alfarje, techamiento que proviene de la arquitectura mudéjar y que, poco usual en el Norte de México (v.g. en San Francisco de Tlaxcala), es contún en Chiapas, Yucatán y Guatemala. Tanto los muros exteriores como la parte alta de las columnatas están caladas por bellísimas ventanas que no solamente aligeran el peso de los muros, sino que le dan más elegancia e iluminación a la iglesia. La fachada está concebiđa igualmente en el estilo regional de Chiapas, Yucatán y la América Central: fachadas que rematan en nichos o espadañas, estilo que ocasionalmente se encuentra en el norte de México en el siglo XVI, para dejar lugar más tarde a las fachadas trabajadas con altas torres laterales. Además, en su decoración aparecen ocasionalmente ladrillos cortados en diamante, lo que sugiere una influencia del constructor de la fuente cercana del lugar, fray Rodrigo de León o el español, como dice Remesal, que la concluyó.

16 Remesal. Ob. Cít. T. II. Pág. 536. 
En el ábside de la iglesia se encuentra la torre del campanario, probablemente obra de modificaciones posteriores. Ên ella se encuentra la monumental campana de la que Ximénez nos trasmitió la noticia de que se fundiera añadiendo el oro de las joyas donadas por los vecinos, liga a la cual se atribuye su espléndida sonoridad; esta campana lleva grabada la fecha de su fundición, 1576.

Un descendimiento en bajorrelieve (Iglesia de El Calvario).

Fuera de Iugar, colocado sobre un altar y sobrepuesto a una cruz, se encuentra actuaimente un magnífico retablo estofado y policromado, representando el Descendimiento de la Cruz, en la iglesia del Calvario en Chiapa. La iglesia en que actualmente se encuentra es de postrimerias de la colonia y de factura popular. El relieve a que nos hemos referido incuestionablemente fué desprendido de algún otro conjunto y trasladado allí en tiempos recientes, quizá durante los últimos coflictos religiosos o bien en los años aciagos del siglo XIX al secularizarse los bienes del clero. Muy probablemente esta espléndida obra de arte, una de las más bellas en su género, proceda del convento dominicano de la misma ciudad.

I. a composición y el desgaste de la policromia acusan una factura muy antigua, quizá del final del siglo XVI, o, a más tardar, de principios del XVII, obra de aquellos escultores que habrán de fundar la escuela escultórica religiosa de Guatemala, 17 La composición es de un sabor fuertemente arcaizante: casi la diriamos inspirada en una lámina de los primitivos flamencos. E1 rostro de Cristo, la Dolorosa, son cuadros de una profundidad psicológica inestimable; los personajes del fondo, de rostros acentuadamente $\mathrm{j}$ udios, los diriamos bebidos de la realidad.

Respecto al autor de este retablo, que hemos supuesto formara parte del retablo principal del convento de Santo Domingo de Chiapa, sólo podriamos aventurar que fuera obra de los frailes salmantinos fray Melchor Gómez y fray Juan Alonso, a quienes Remesal hemos visto atribuye el aderezo de los retablos de la iglesia.

17 Nuestro retablo guarda semejanzas puramente formales con un retablo de monjas clarisas que se conserva en el Museo de Antigua Guatemala: éste. sin embargo, es obra de principios del siglo XVIII y no es politromado ni estofado. 


\section{La Fuente de Chiapa.}

La fucnte colonial de Chiapa es tuno de los monumentos que se han considerado con justicia como más importantes no sólo del arte en México, sino en América.

Ignoramos en qué año se empezó a construir esta fuente, pero fué seguramente en años posteriores a 1545, ya que en este año el encomendero del lugar señalaba sitio para convento en el lugar "donde hay una fuentecilla". Como sabemos, el convento fué construído cercanamente evitando así los males que se causarian a los indigenas restándoles su precioso manantial. Consta que en 1562 fué concluida esta obra que comenzara fray Rodrigo de León: "A los de Chiapa -dice Remesal- se les añadió otra ocasión de contento y alegria en el fin del oficio de la fuente que está enmedio de la plaza, que es uno de los buenos y bien trazados que hay en todas las Indias, trazóle y comenzóle el padre Fray Rodrigo de León y en ausencia suya le prosiguió un español hasta echarle este año de 1562 el agua”. 18

La fuente está construida en estilo mudéjar y está concebida en forma de una capilla cuya bóveda, que sostienen ocho arcos de medio punto, recubre el brocal de la fuente; el empuje de la bóveda, está sostenido por ocho botareles que lo son de medio punto, igualmente, excepto uno de ellos que se convierte en un elevado y elegante torreón en cuyo interior existe una escalera de caracol; toda la fuente está trabajada con ladrillo --un material tan querido de la arquitectura arábigo-española-, ladrillo que en todo el exterior está cortadio en puntas de diamante para stu decoración; tanto el exterior de la bóveda como el renate de los botareles está coronado de almenas decorativas.

18 Remesal. Ob. Cit. T. II. Pág. 422. De este Fray Rodrigo de León dice un bistoriador moderno de Chiapas. Téffilo Antonio Orantes, en la Histotia manuscrita que the facilitara el Sr. Bernardo Reyes, "que no concluyó (la fuente) por haber pasado a Tecpatian a dirigir la grande obra del Convento de Santo Domingo cuyas ruinas manifiestan los grandes conocimientos arquitectónicos de su autor". Por no indicar Orantes la fuente histórica de que tomó la noticia, la tomamos con toda reserva, a pesar de las semejanzas exteknas, máxime que Remesal dice que hacia 1562 "el padre fray Alonso de Villava se daba este año mucha prisa en proseguir y acabar las iglesias de los zoques”. (T. II. Pág. 422). 


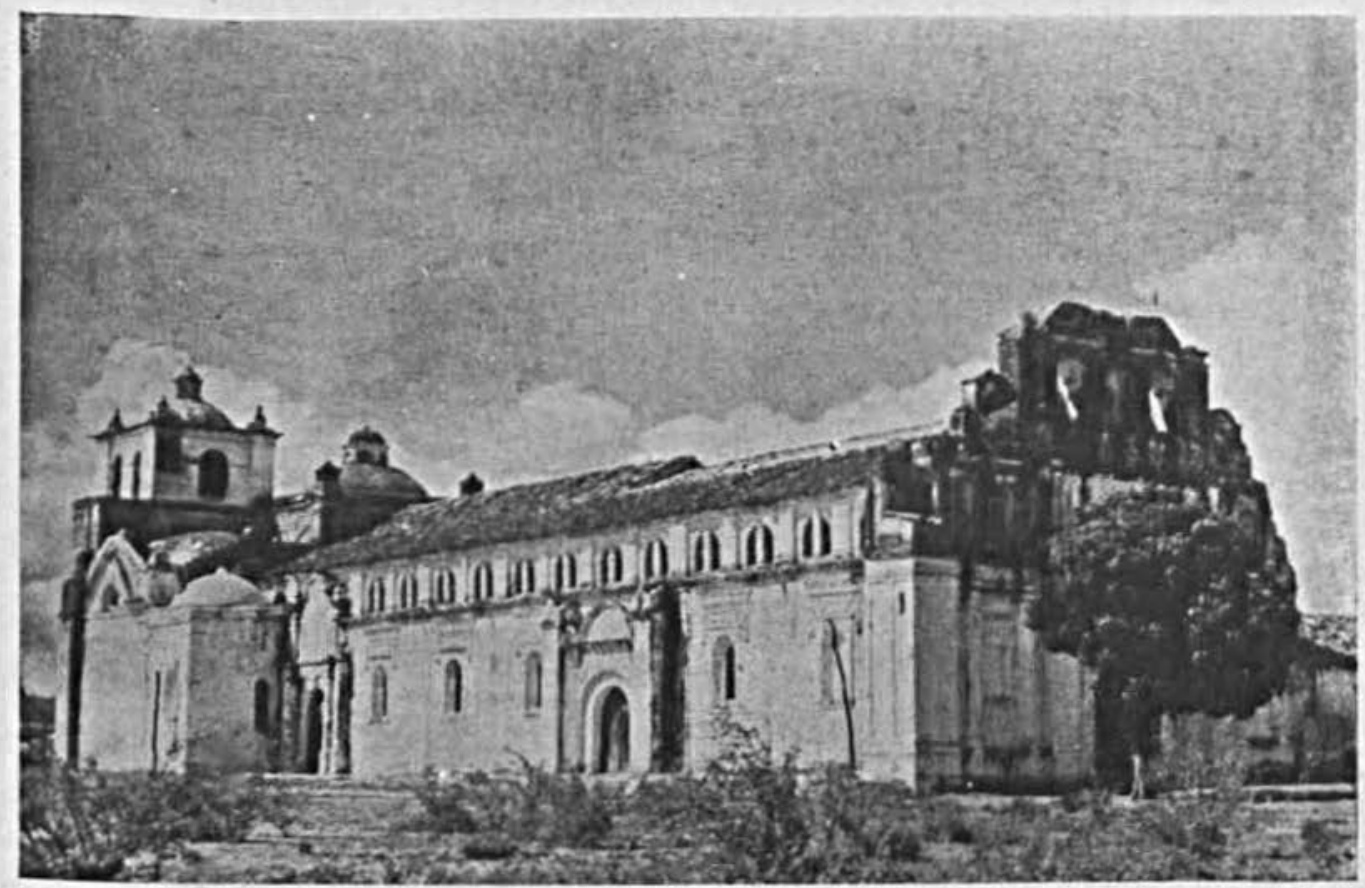

Fig. 1. Iglesia del convento dominicano de Chiapa de Corzo, Chis. ¿1554-72? Fray Pedro Barrientos. (Fotografias de S. Toscano) 


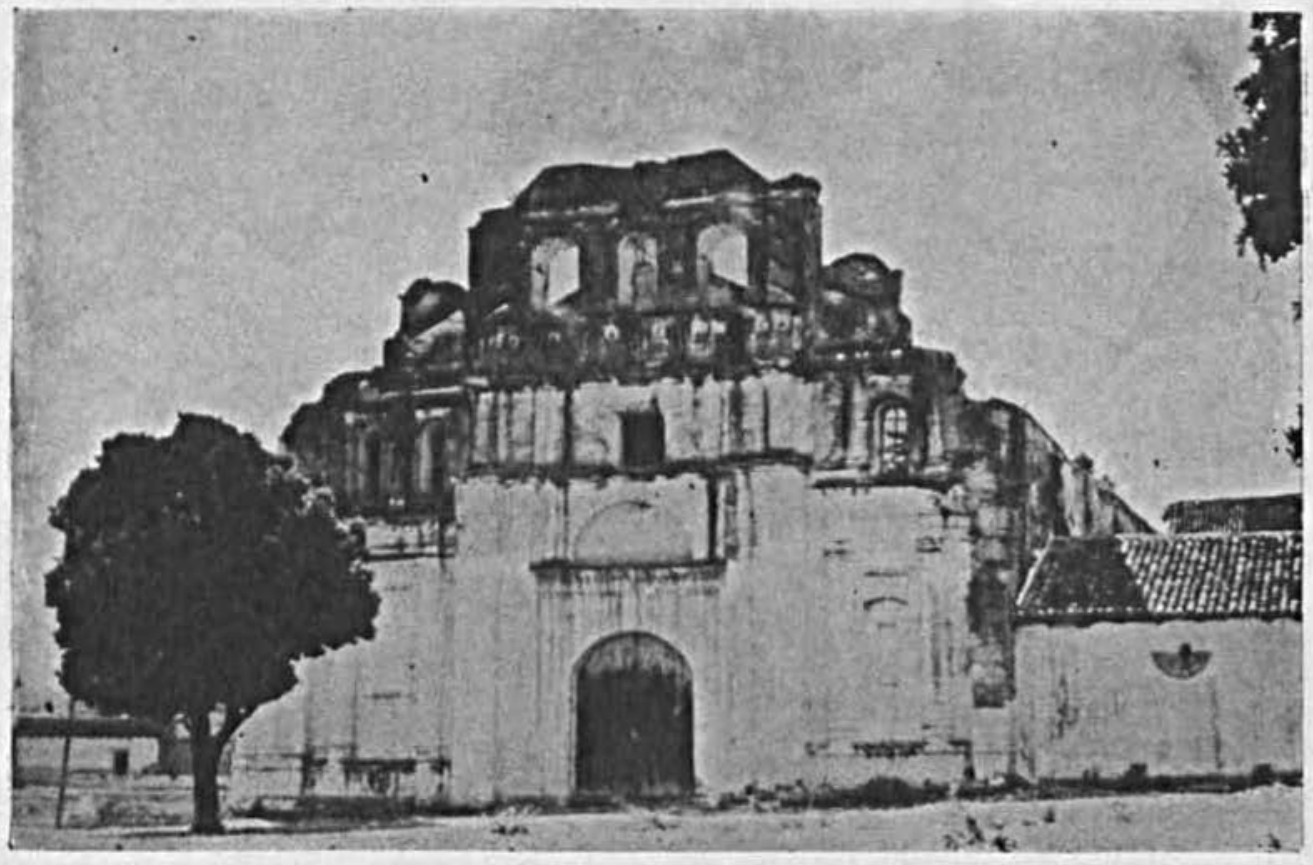

Fig. 2. Fachada de la iglesia 


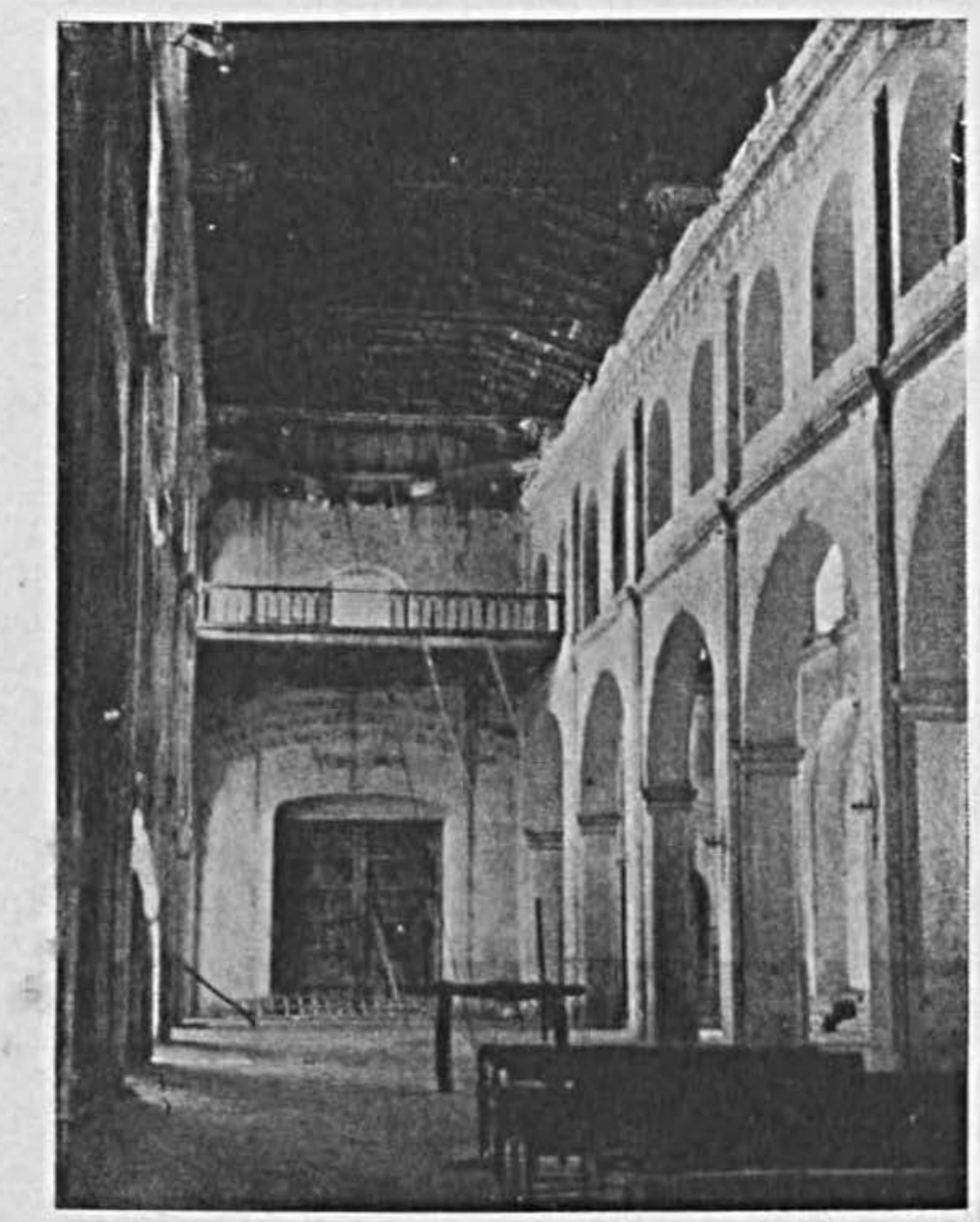

Fig. 3. Interior de la iglesia del convento de Chiapa 


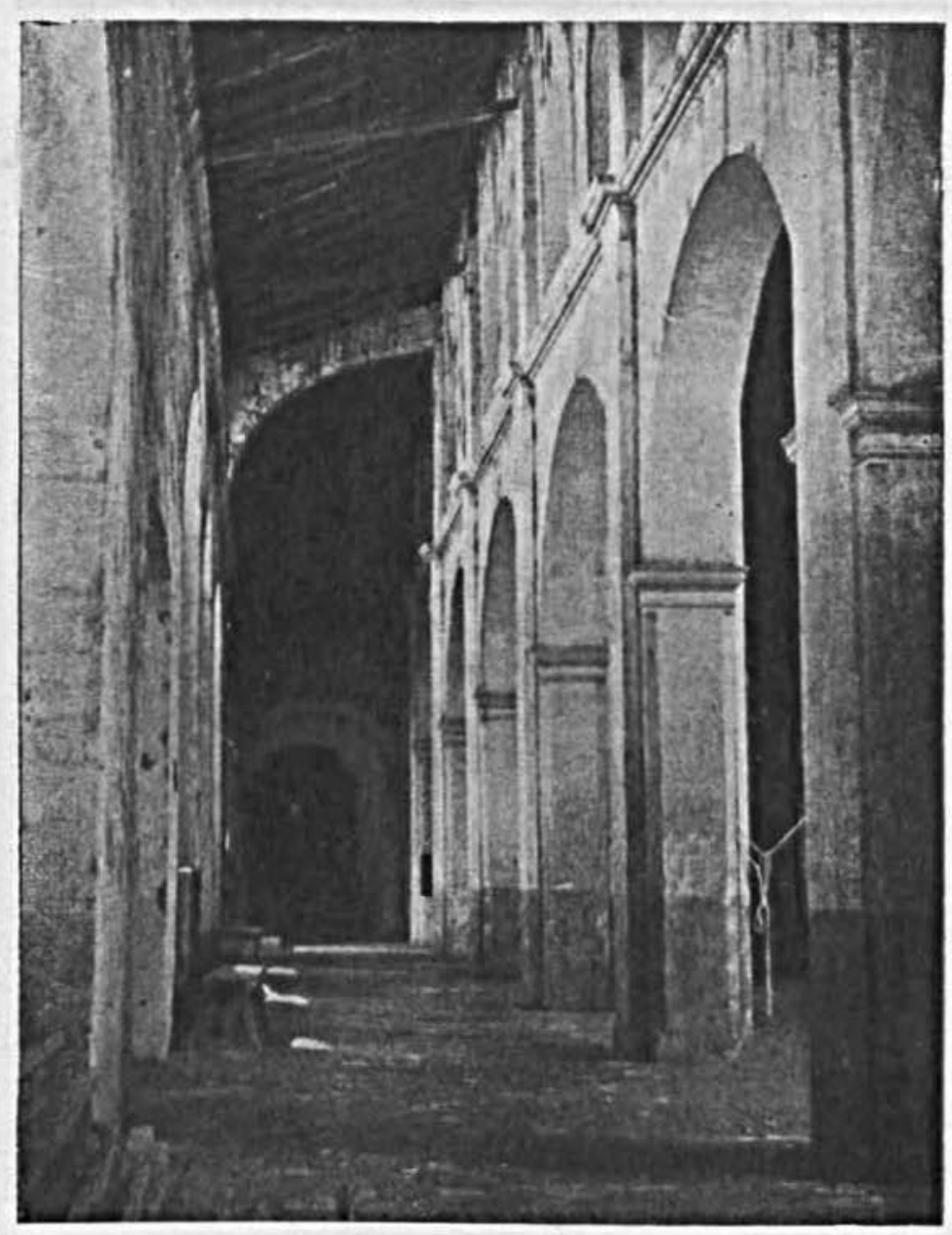

Fig. 4. Nave lateral de la iglesia de Chiapa 


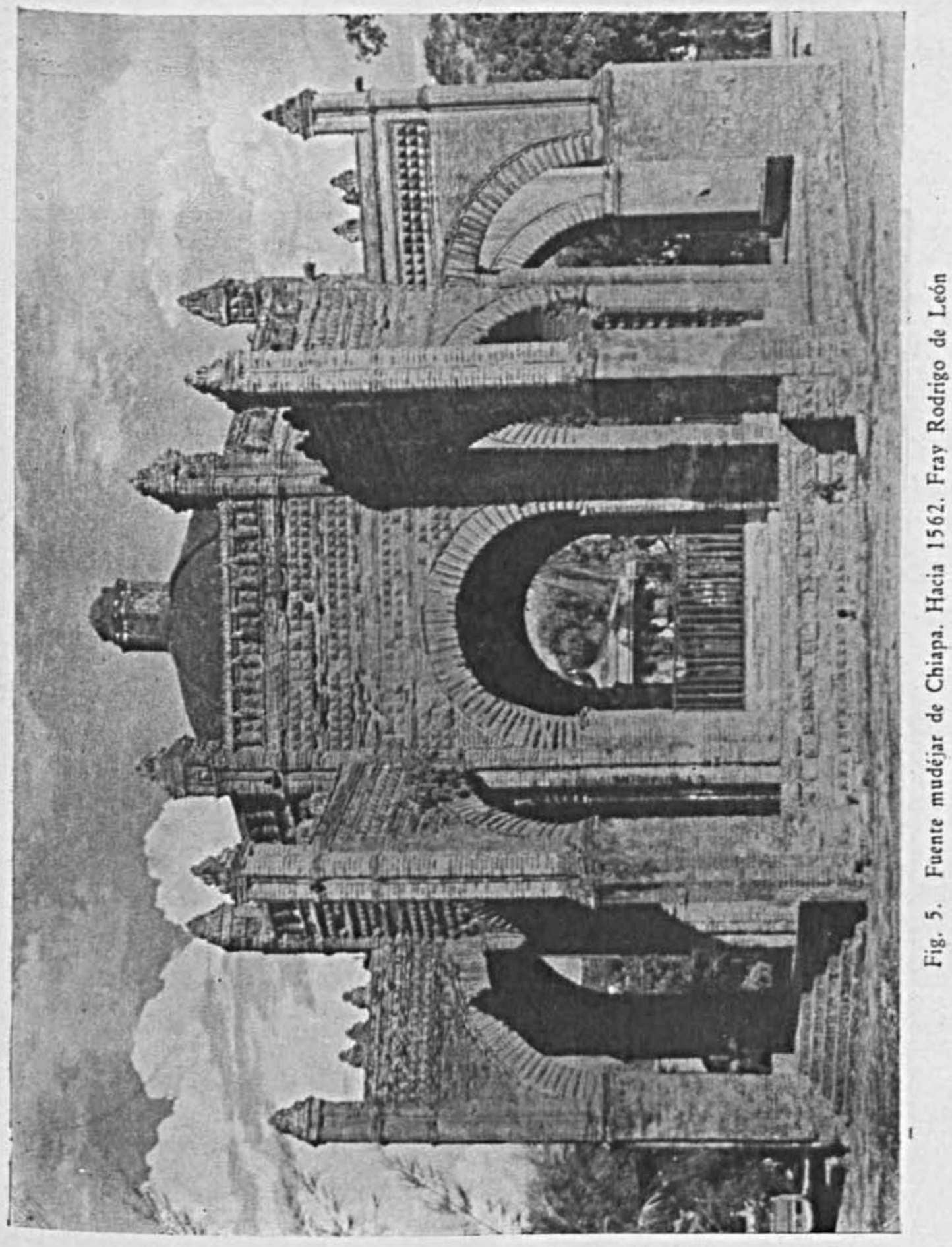




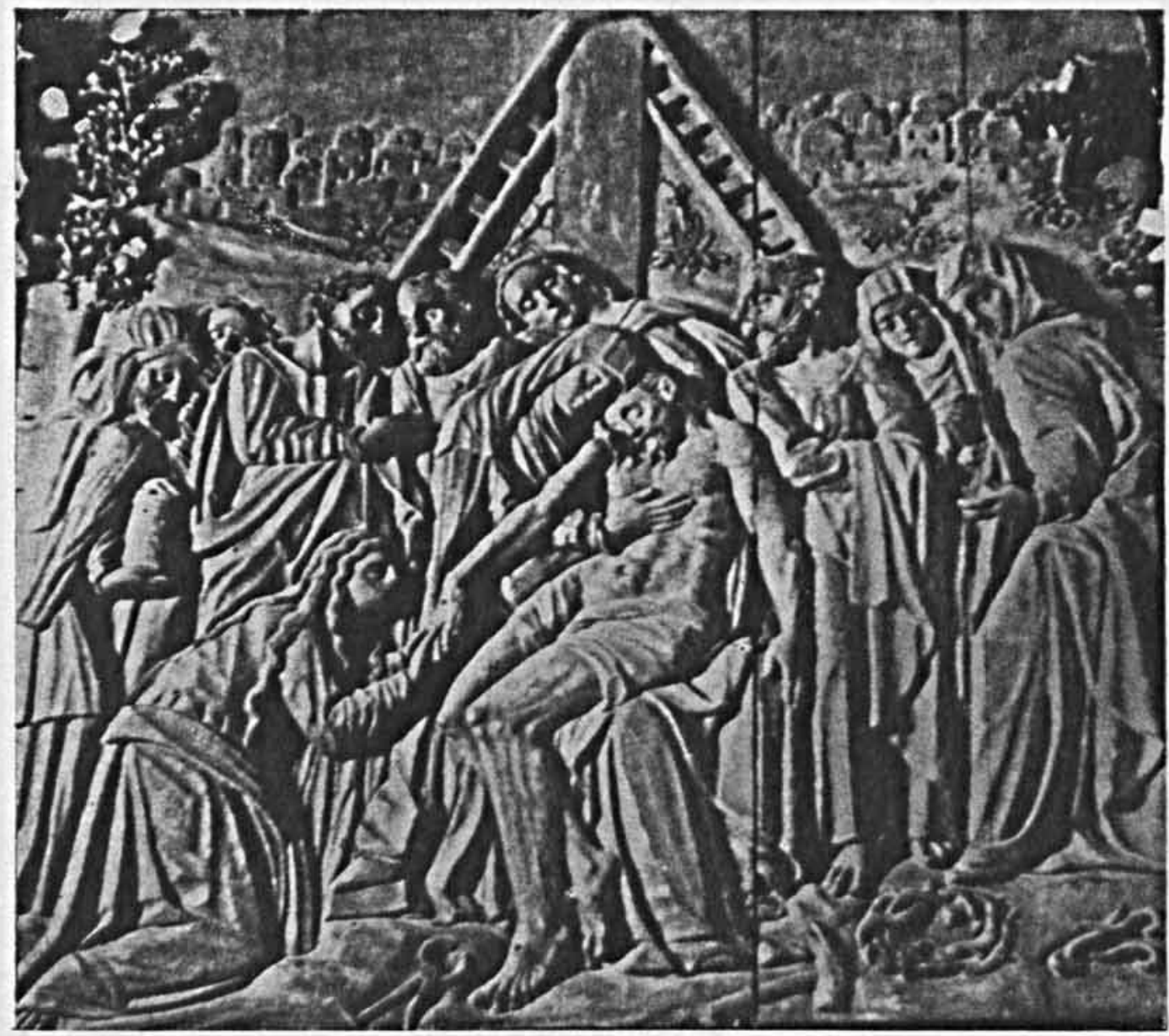

Fig. 6. "Descendimiento" ¿Siglos XVI, XVII? Iglesia del Calvario. Chiapa de Corzo, Chis. 


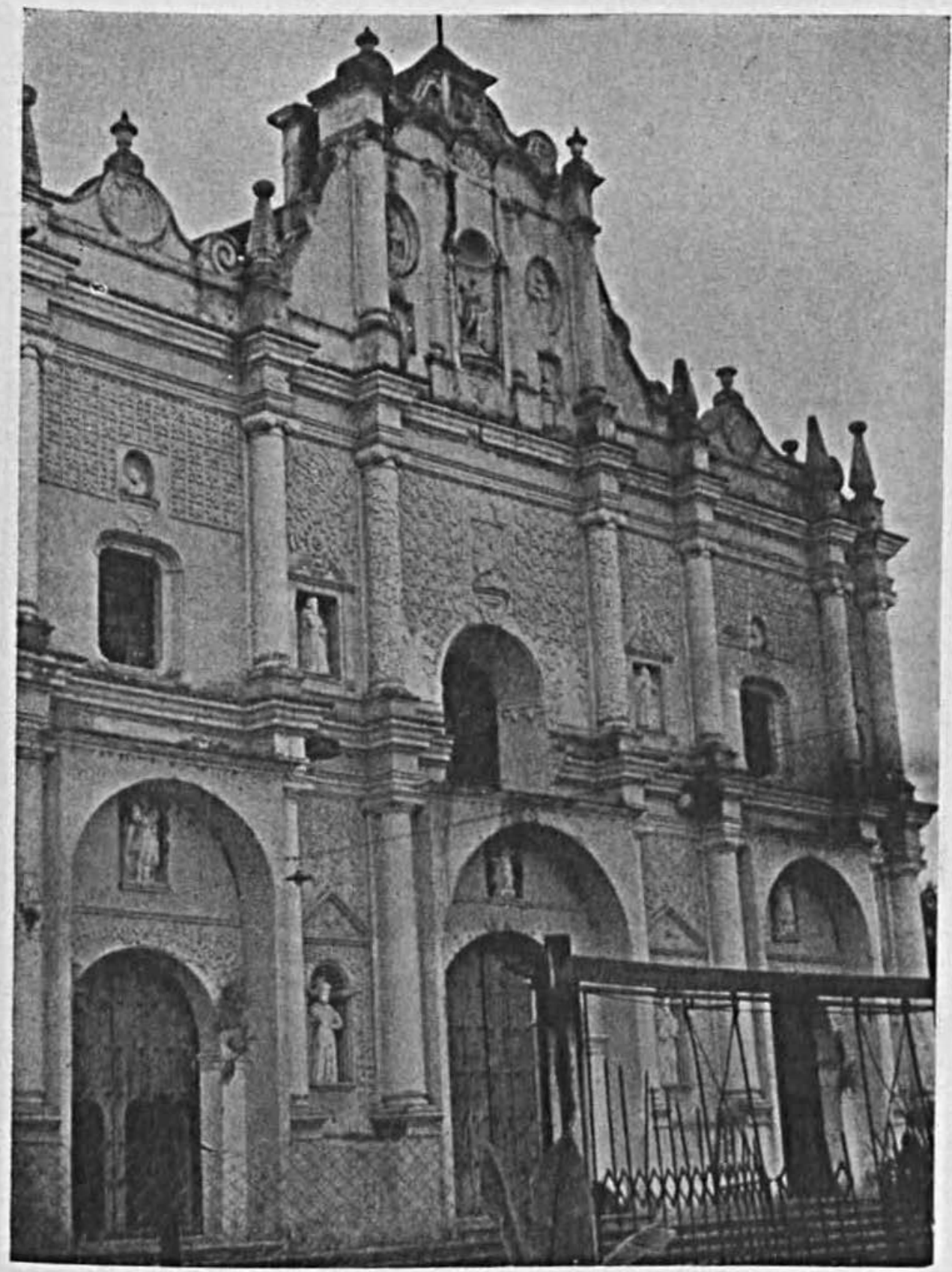

Fig. 7. Fachada de la catedral. Siglo XVII (?) San Cristóbal las Casas, Chis. 


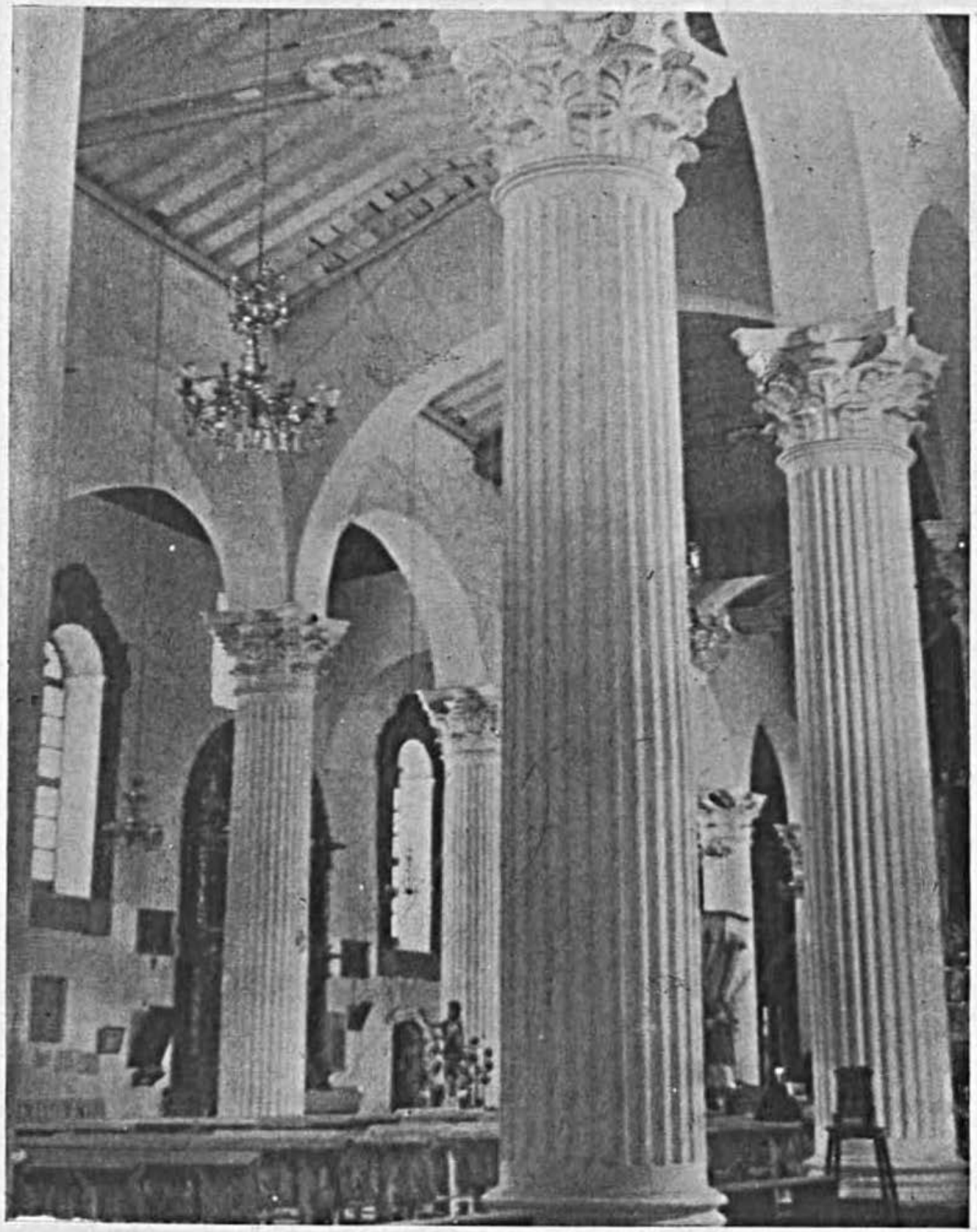

Fig. 8. Interior de la catedral. San Cristóbal las Casas, Chis. 


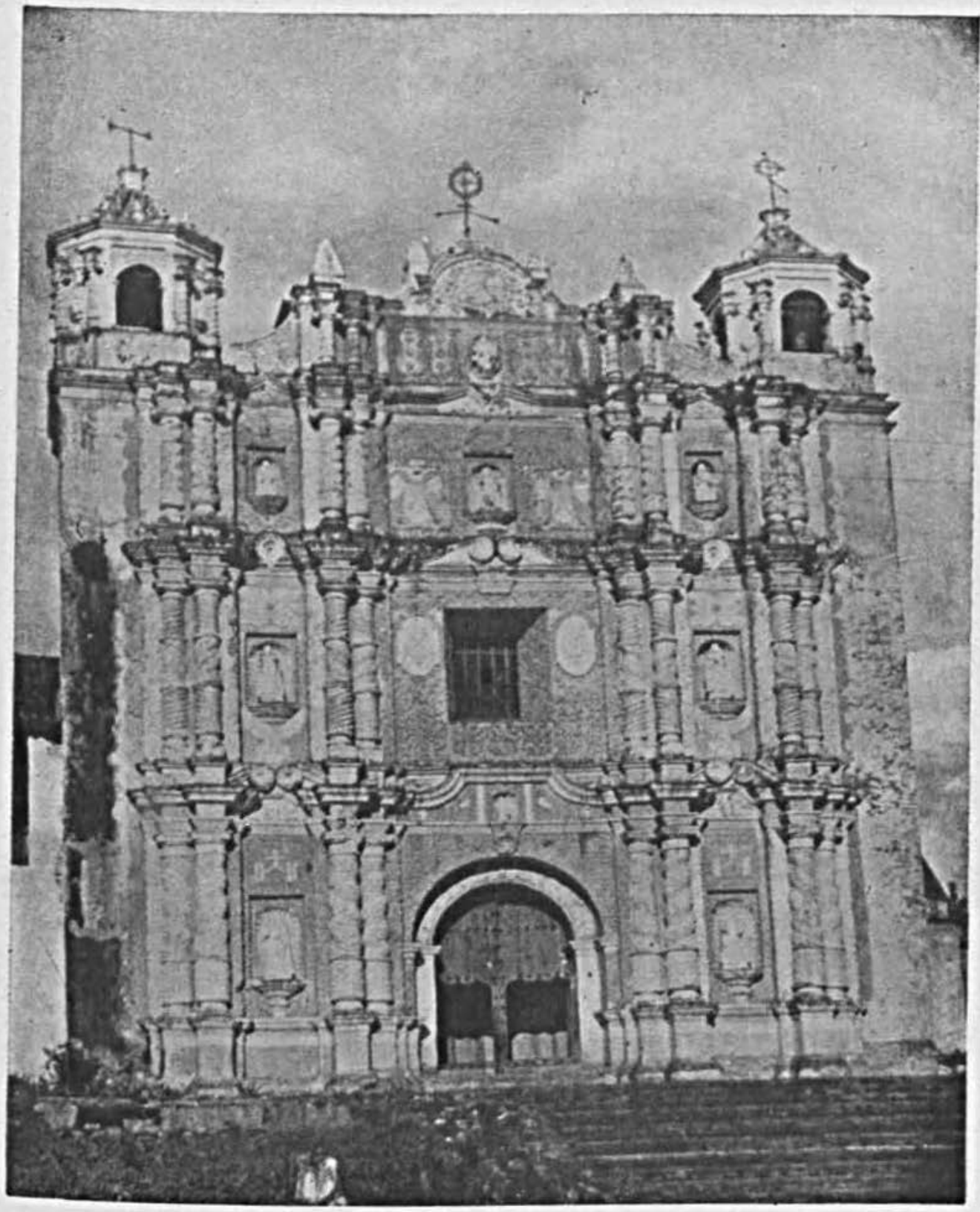

Fig. 9. Iglesia de Santo Domingo. Siglo XVII. San Cristóbal las Casas, Chis. 


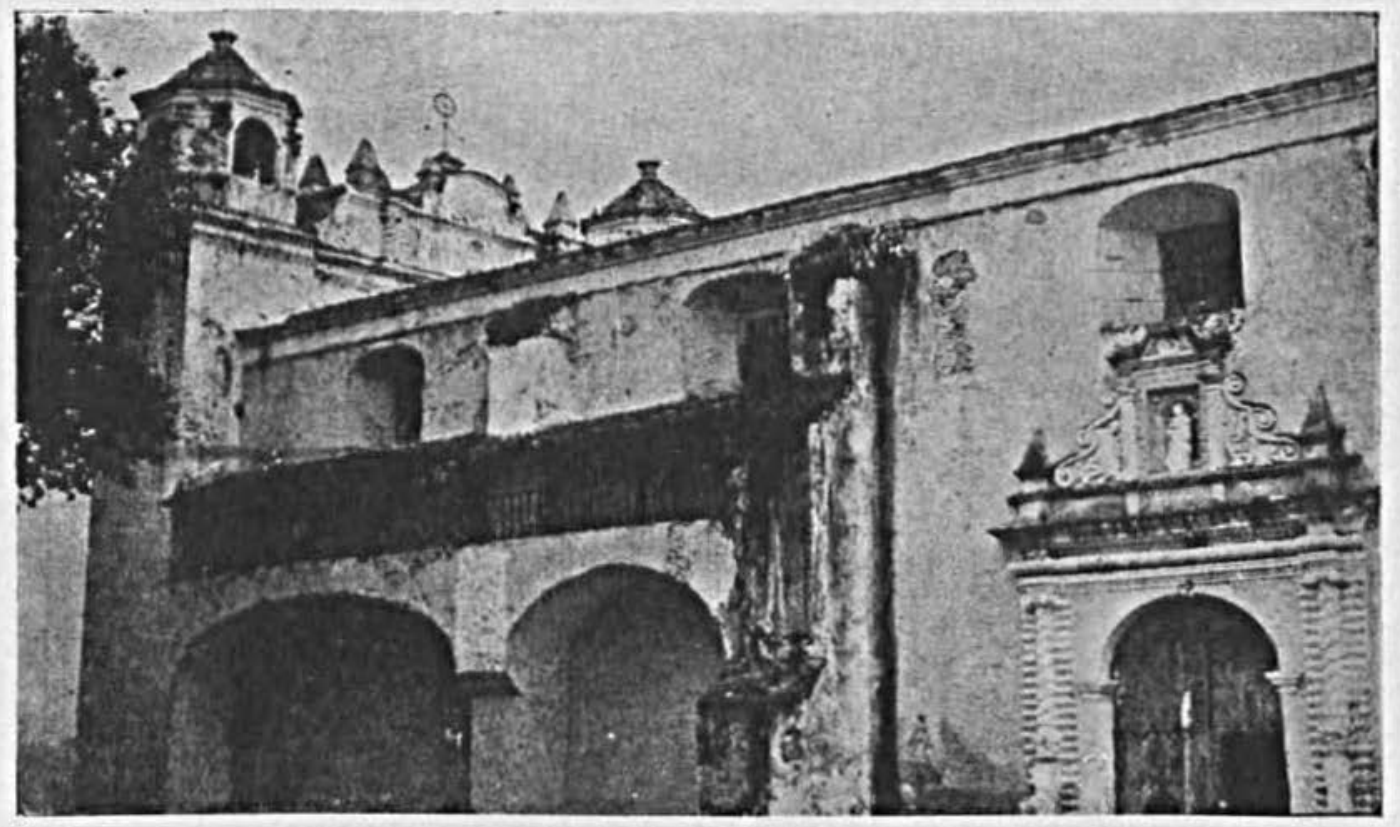

Fig. 10. Vista lateral de la iglesia de Santo Domingo. San Cristóbal las Casas, Chis. 


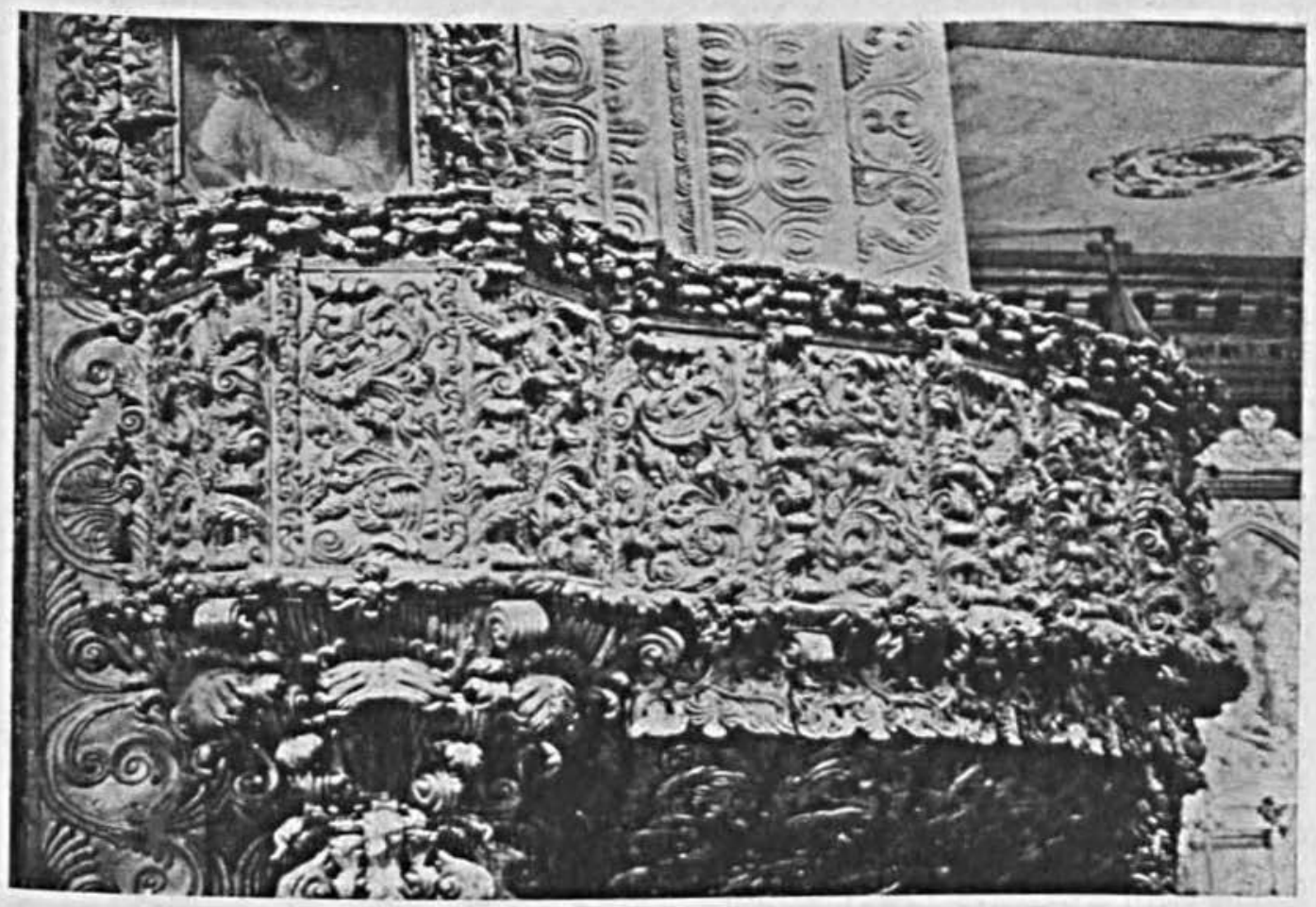

Fig. 11. Púlpito barroco de Sto. Domingo. San Cristóbal las Casas, Chis. 


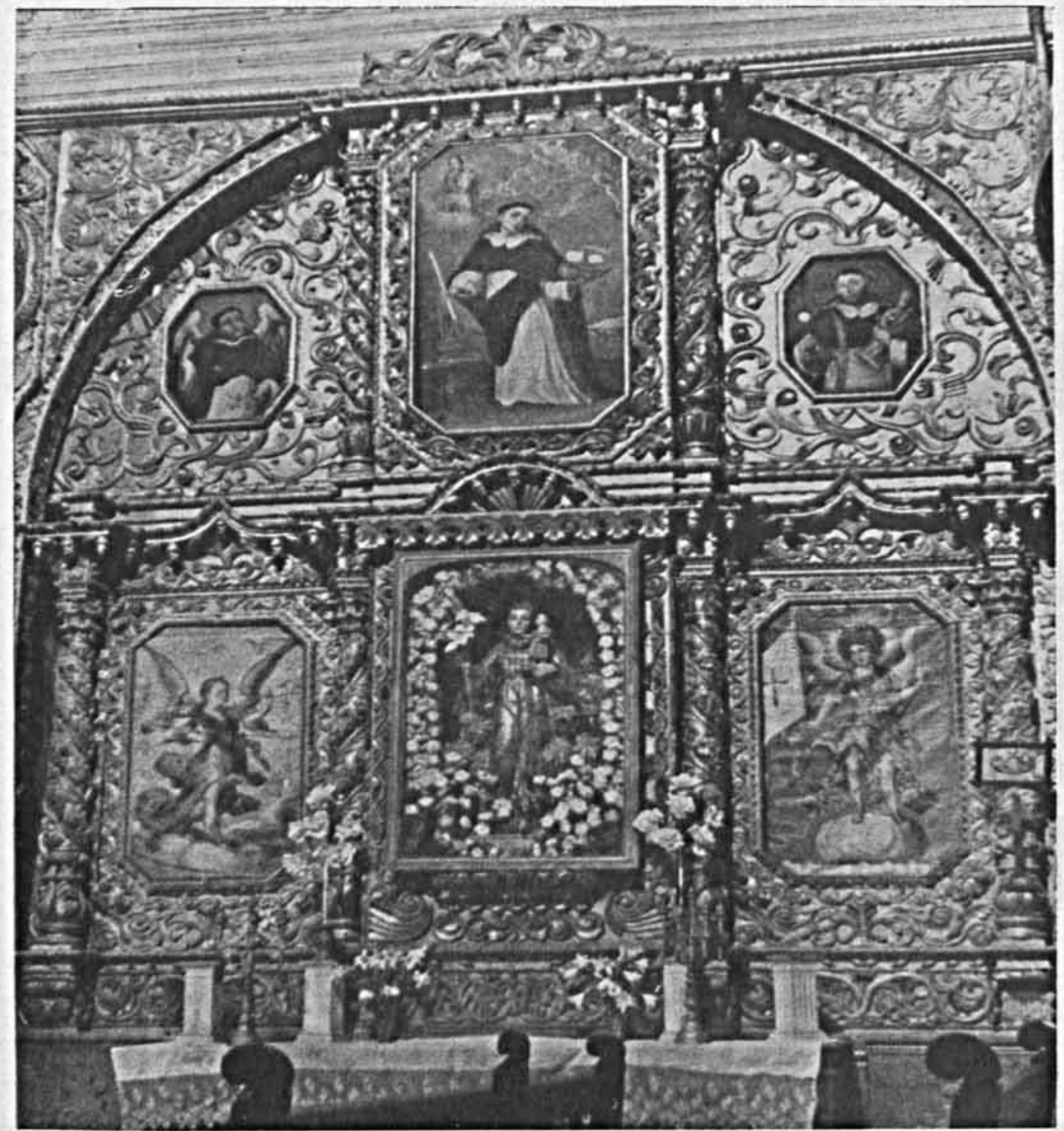

Fig. 12. Retablo en la iglesia de Santo Domingo. San Cristóbal las Casas, Chis. 


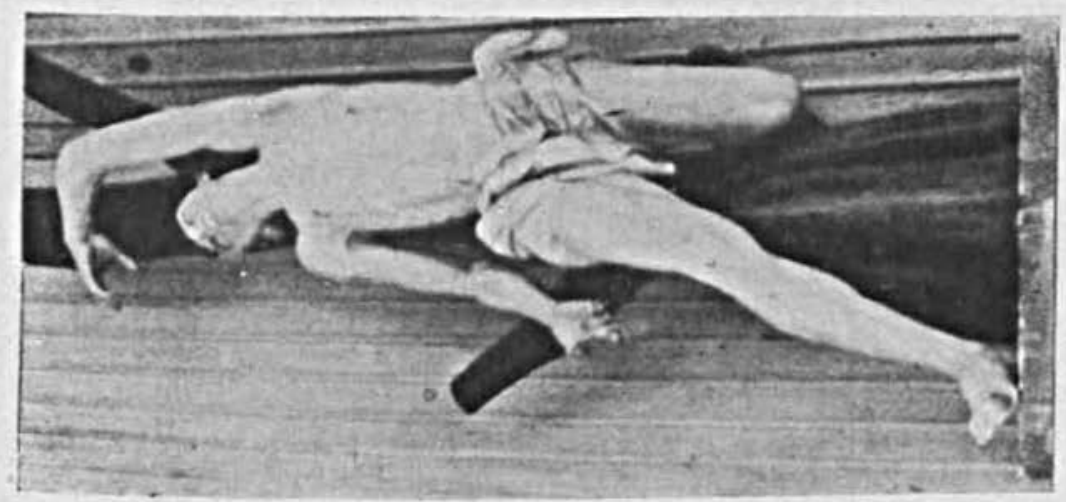

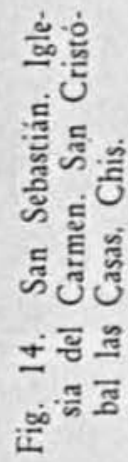

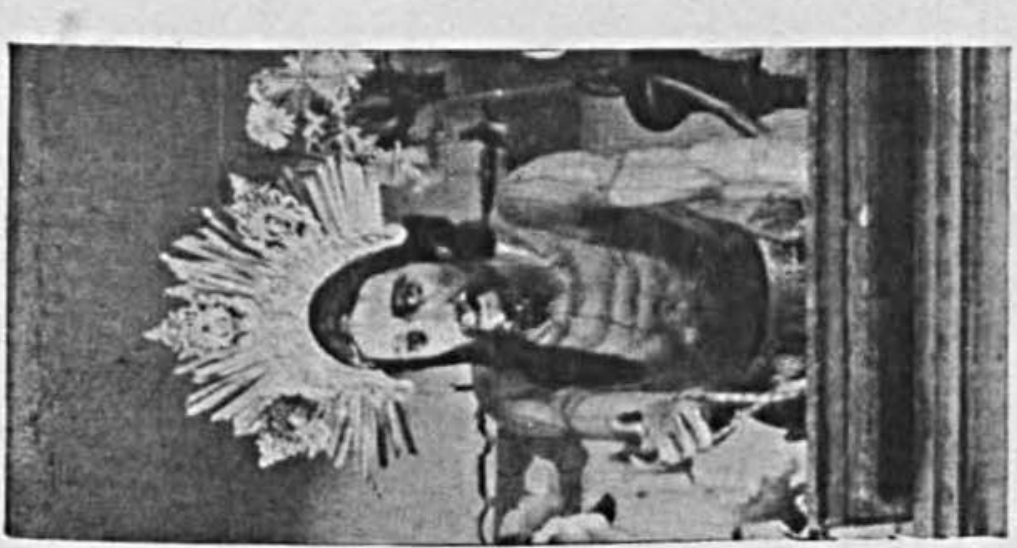

宕泣宁 虫 ํㅠㄹㄴㅠㅠ है. 응

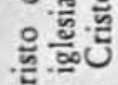
U

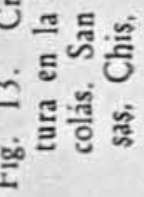




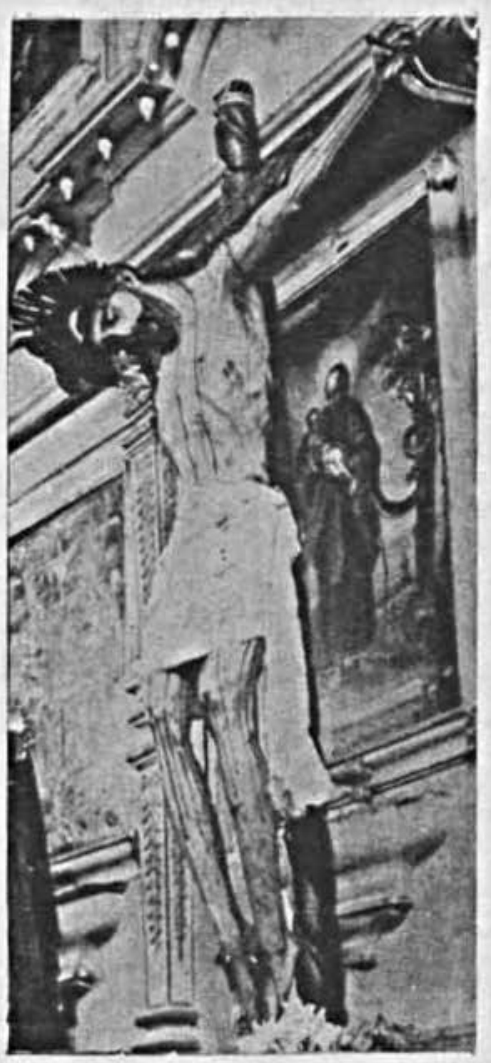

Fig. 15. Cristo en la cruz. Iglesia del Carmen. San Cristóbal las Casas, Chis.

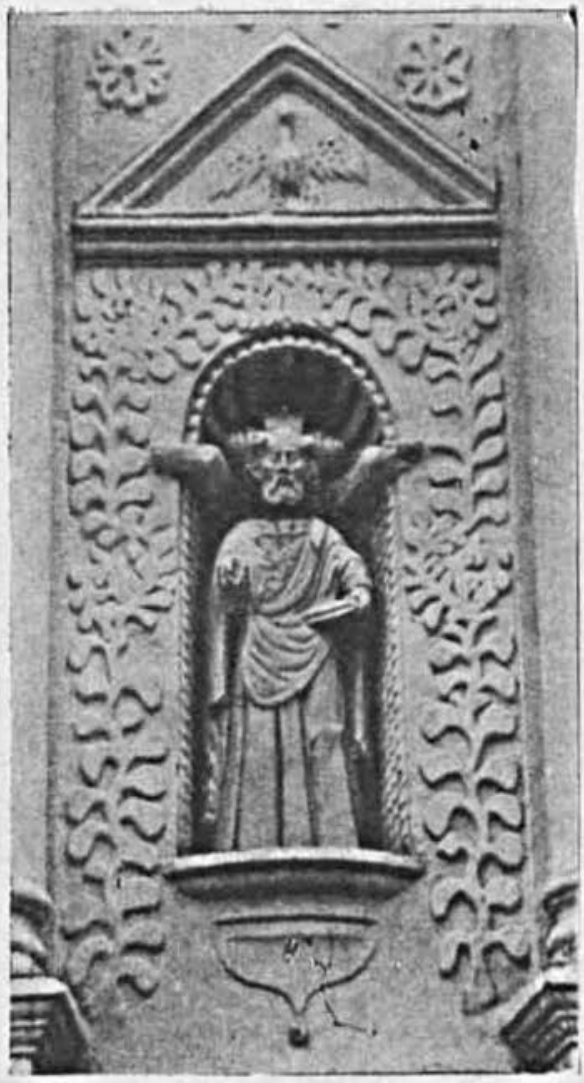

Fig. 16. Escultura de la fachada de la catedral, San Cristóbal las Casas, Chis. 


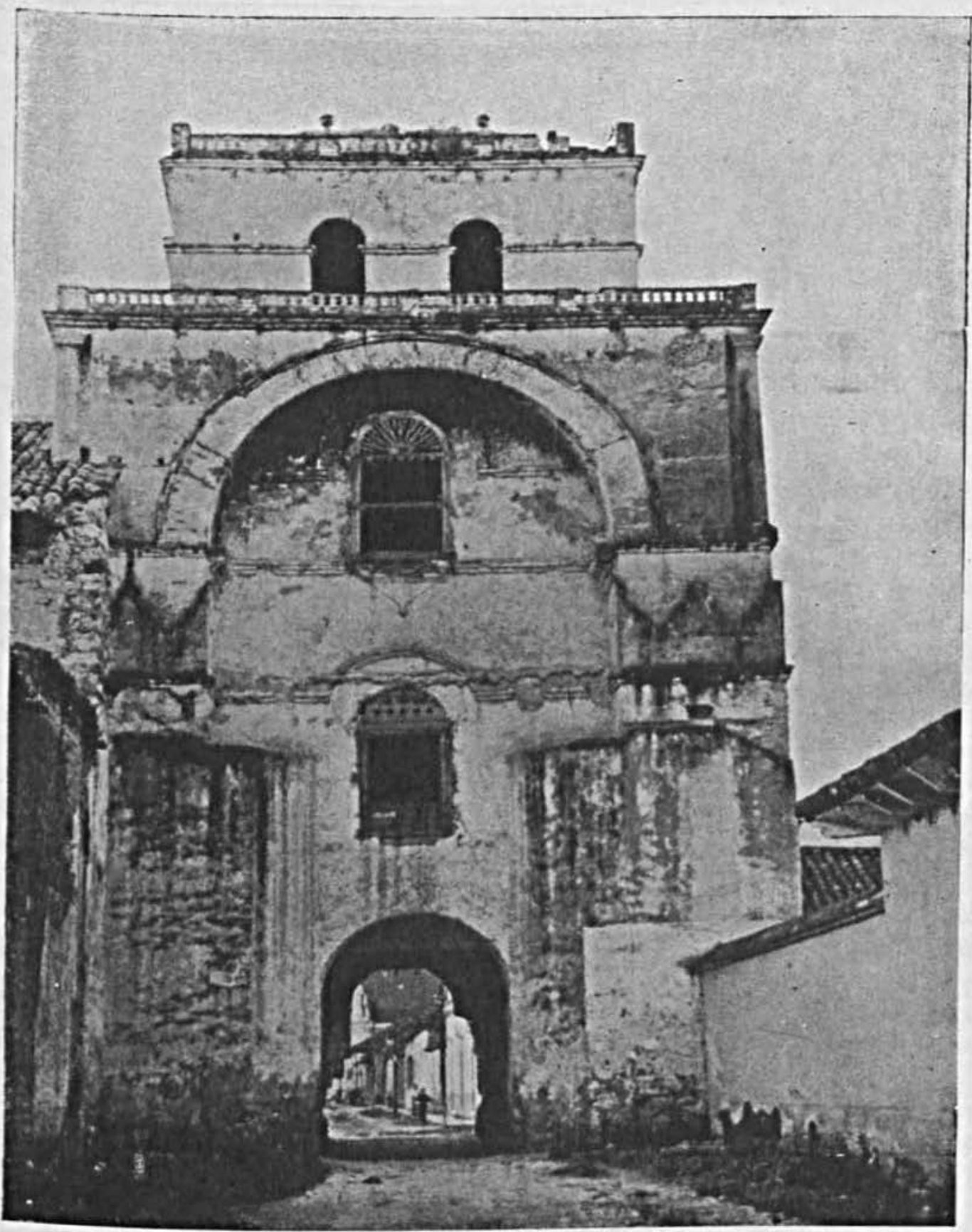

Fig. 17. Torre y campanario de la iglesia del convento de la Encarnación (El Carmen). San Cristóbal las Casas, Chis. Siglo XVII 


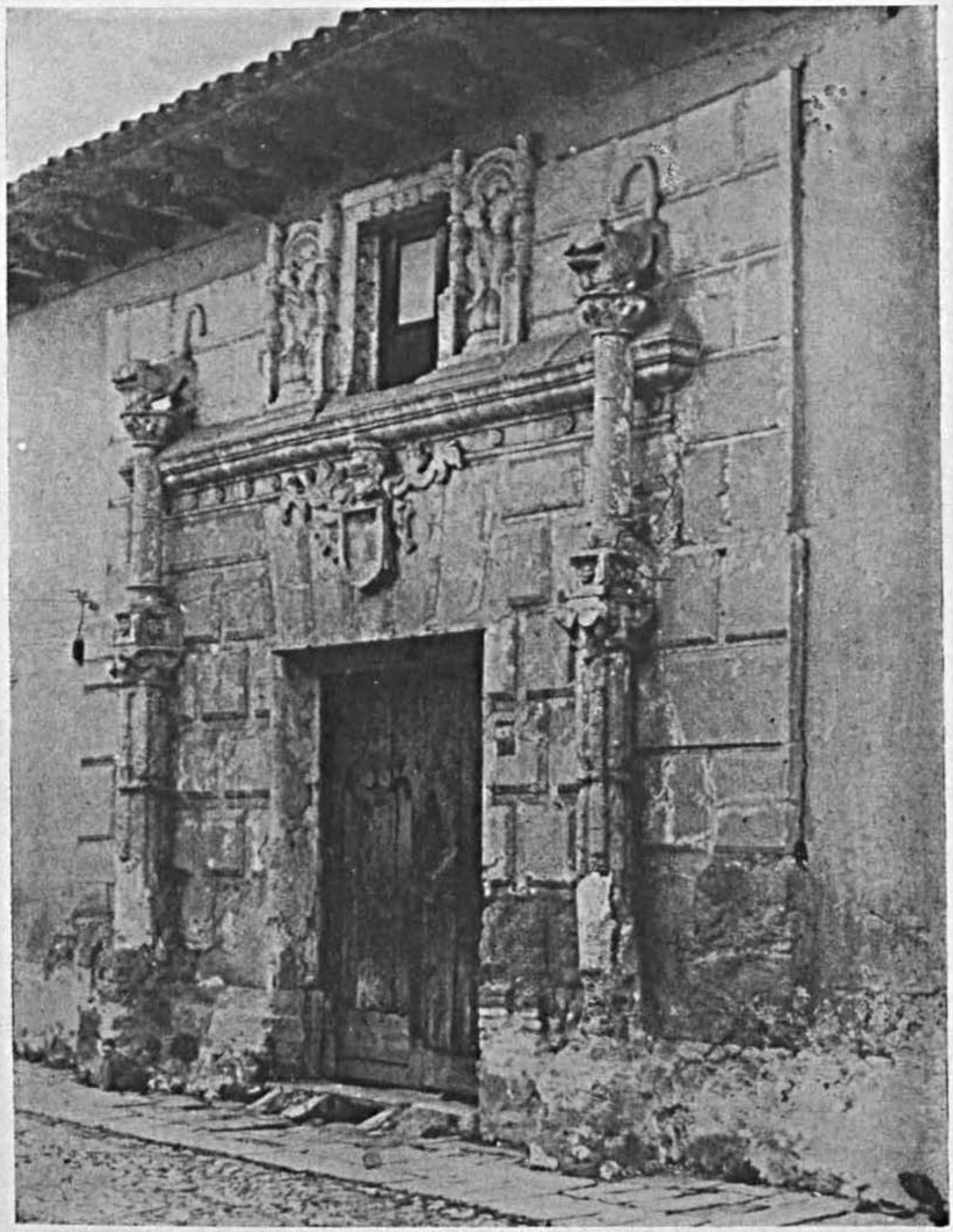

Fig. 18. Portada plateresca de la casa de don Andrés de la Tobilla (?) Siglo XVI. San Cristóbal las Casas, Chis. 


\section{La Catedral.}

Fundada la Villa Real lo primero que hicieron los pobladores fué señalar sitio para la fundación de su iglesia, la que dedicaron a la Virgen, por lo que se le llamaba de Nuestra Señora de la Anunciación. En 1536 se le cambió advocación a San Cristóbal y así se le llamó en la bula de Paulo III que en 1538 la erigió en catedral. No obstante y a pesar del empeño del cabildo, la nueva catedral no pasaba de ser una humilde construcción.

En 1545 fué descrita por fray Tomás de la Torre, uno de los primitivos dominicos que llegaron con el P. Las Casas a la evangelización de aqueilas regiones. Ximénez, que tuvo en sus manos el original, transcribe las palabras en su historia: "Hay en esta ciudad una bonica Yglesia, bien labrada, de madera, cubierta de teja, las paredes son de adobe y ladrillo, digo bonica para según son las Yglesias de aquella tierra y en los pueblos de españoles, aunque sus casas son asás soberbias, galanas y costosas, como parece en México". 19

Esta-humilde iglesia fué el principio de la actual catedral, pero ésta es, sin duda; obra del siglo XVII y pertenece al barroco moderato de aquella época. La conjetura del $\mathrm{Sr}$ : Toussaint me parece que es exacta por corresponder las fechas a la época probable de más intensa reconstrucción de la catedral: "Pues quizá refiriéndose a ésta dice Vera que cooperó al engrandecimiento material de la fábrica el Sr. Marcos Ramirez de prado que gobernó de 1635 a $1639 " .20$

Su exterior está concebido dentro de la modalidad barroca, poco desenvueltia, del siglo XVII: colimnnas ornamentales, nichos con santos: en los intercolumnios, remate central sobre los dos cuerpos dórico y jónico de la fachada, etc. Este barroco pertenece a la tradición mexicana que se extiende hasta la América Central - v.g., debe compararse con la fachada de la catedral de Antigua, Guatemala.

El interior, sumamente modificado en épocas recientes, está trazado en ia habitual forma de una basilica dividida a tres naves por columnas

19 Ximénez. Ob. Cit. T. I. Pag. 475.

20 Las Iglesias de México, Vol. VI, 1525-1925. México, 1927. Pág. 66. 
corintias que soportan la techumbre de alfarje. Los tres retablos del fondo y el púlpito son de los escasos elementos primitivos que conserva la catedral; los tres, sin embargo, están tallados y estofados al uso barroco de finales del siglo XVII o principios del XVIII, decorado con figuras de santos y con pinturas, aunque aquéllas de mejor calidad que éstas.

El padre Vicente Andrade menciona por 1913 los siguientes tesoros catedralicios: "Una granada de plata, única en el mundo, mandada fa. bricar por el Ilmo. Sr. Moctezuma a nediados del siglo XVII: sus gajos se abren lentamente y en la parte superior aparece la custodia... y una magnifica pintura de Santa María Magdalena con la firma del célebre pintor oaxaqueño Miguel Cabrera". 21.

El primero de los objetos nencionados actualmente ha desaparecido, pues fué substraído por las fuerzas revolucionarias hacia 1915, restando sólo la pintura de Miguel Cabrera, que se conserva en la Sacristía. 22

Iglesia y Convento de la Merced.

Tocó a una orden menor, a la de los mercedarios, ser la primera en tiempo en evangelizar la región de Chiapas. Debieron llegar a fines de 1537 o a principios de 1538 a Ciudad Real (San Cristóbal), traidos por el obispo de Guatemala, Marroquin, cuando éste volvió de México después de consagrarse y por no haber encontrado frailes de las órdenes mayores en posibilidad: "Se fundó el año pasado de 1537 el convento de Nuestra Señora de la Merced de Ciudad Real, siendo su priner conendador el P. Fray Pedro de Barrientos..." 23

Continúa Remesal y nos dice que hacia 1545 en que llegaron los dominicos "Los padres de la Merced tenían a la sazón convento en Ciudad Real, cuatro religiosos y su prelado, fray Marcos Pérez Dardón. 24 Al acercarse el padre Las Casas los mercedarios pretendieron despoblar

21. Yicente de P. Andrade: Mi Excursión. a Chiapas. Guadalupe Hidalgo, D. F.. 1914. Págs. 25-26.

22 Dato proporcionado por el Director del Museo Regional de Chiapas, don Bernardo Reyes, a quien nos honramos en hacer público nuestro reconocimiento por los datos y publicaciones que a nosotros hiciera llegar.

23 Remesal. Ob. Cit. T. I. Pág. 218 . Pox etror alude a Fray Pedto de Barrientos, éste fué dominico y llegó en 1554; casi es seguro qué se refiera a Fray Marcos Pérez Dardón.

24 Remesal, Ob. Cit. T. I. Pág. 405. 
aquella región e irse a Copanaluuastla, lo que impidió el propio fray Bartolomé. Pero las rivalidades entre las órdenes religiosas más antiguas no concluyeron e insensiblemente la orclen menor, la de los mercedarios, fué confinada y reducida a la más obscura y precaria situación. En 1625 en que estuvo por San Cristóbal Tomás Gage, acaso por su pobreza ni siquiera menciona el convento.

Consecuentemente a la penturia de la orden, el convento y la iglesia de los mercedarios debió haber sido muy pobre materialmente en el sigio XVI y en los siglos siguientes. La fachada de la iglesia ha sido renovada en el siglo XIX o en el presente, separándose del estilo habitual de aquella región por el empleo de dos altas torres; igualmente su interior es pobre y carece de interés. El convento fué aprovechado para cuartel en la segunda mitad del siglo pasado y renovada st fachada para adaptarla a fines militares; actualmente está abandonado y en ruinas.

\section{Iglesia y Convento de Santo Domingo.}

Fué el convento de San Cristobal la primera casa fundada en Chiapas por los dominicos, quienes arribaron en 1545 y consta que en 1547 el obispo Marroquín ponía la primera piedra; pero debió ser tan pobre aquella construcción que en 1548: "Ydo el visitador y tornados a derramar los padres al fin de la predicación, noche de Epifanía, se nos cayó nuestra Yglesia y parte de la Casa". 25 Consta por el mismo Remesal que ya en 1549 trabajaban en su nuevo convento, pero reconoce que no debería ser permanente, ya que estaban mal cimentados sus muros y la humedad constantemente los amenazaba: "Andaban muy cuidadosos con el edificio de st Casa... Pero en fin se aderezó de suerte que de allí en adelante tuvieron forma de Casa y Clausura, y puertas y ventanas en las celdas y corrales cerrados, que comenzaban a querer ser huertas..." 26 Consta por el cronista mencionado el nombre del improvisado arquitecto $y$ el ano en que concluía la primitiva iglesia: "Dejó al padre Fray Pedro de la Cruz acabado el cuerpo de la Iglesia y lo príncipal del Convento". 27

\section{T. I. Pág. 475.}

26 Remesal. Ob. Cit. T. H. Pág. 236 27 Remesat. Ob. Cit. T. II. Pág. 406. De fray Pedro de la Cruz nos dice
el cronista de Chiapas que fué el constructor de la fuente de Cínacantán "tan bien
teazada en trazada en aquellos tiempos $y$ en estos no tan perdida, que no ge iguale con las bue. 
De la prinitiva iglesia y de su convento poco o nada resta a nuestros dias, pues ni siquiera la traza de la iglesia, por tener crucero, nos indica que pertenezca al siglo XVI. Con el crecimiento y enriquecimiento de Ciudad Real, aquella construcción debió aparecer pobre a los ojos de sus pobladores, iniciándose la actual iglesia que es, incuestionablemente, obra del siglo XVII - semejantes posibilidades existen respecto al convento hoy destinado a cuartel.

Remesal, que escribía su crónica en 1619 , nada nos dice de la belleza de su portada e iglesia, así que debemos fijar el periodo constructivo entre esta fecha y 1700, ya que el decorado de la fachada lleva águila bicápites de los Austria, rama extinguida en España precisamente en aquel año.

La fachada es de tres cuerpos, con nichos con santos en los intercolumnios, en orden salomónico; remata en un cuerpo central a cuyos lados están dos torres bajas y pesadas, en un estilo y disposición que se encuentra desde Oaxaca (La Catedral, v.g.) pasando por Chiapas a Guatemala (La Merced, Santo Domingo, en Antigua). Campanarios bajos, chaparrones, cuya belleza descansa en su solidez y en su amplitud. Todos los espacios vacíos los cubren arabescos de argamasa, un estilo que corre desde México en la arquitectura popular (Texcoco, Papalotla, Atlixco) a Chiapas (Santo Domingo, San Agustín) a Guatemala (Catedral de Quetzaltenango, la Merced en Antigua, etc.).

La planta es en cruz latina, una gran nave con crucero aquélla, la única en la ciudad, cerrada con bóveda de cañón. El crucero con una tosca bóveda sin cimborrio. Es, además, el interior barroco mús completo de la ciudad: posee interesantes retablos que probablemente sean obra del siglo XVIII, aunque sin resentir la exuberancia y riqueza del churriguera de la meseta mexicana. Igualmente son de escaso valor sus pinturas. E1 púlpito es obra, igualmente, del periodo ultrabarroco y está relacionado, como observa el Señor Toussaint, con los púlpitos sudamericanos, de los cuales el más importante es el de San Blas de Cusco.

nas de España". (Pág, 422). Y añade que acabó las iglesias de los quelenes con mucha perfección y la primera escalera de caracol de la provincia en Chamula: "como la pudiera hacer el mayor oficial de España... que fué en este padre de estimar la gracia que en la arquitectura Nuestro Señor le dió, no lo habiendo jamás aprendido..." (Pág. 422), 
Iglesia y Convento de San Francisco.

Aun cuando el cronista Vázquez señala el año de 1575 como el de la llegada de los padres franciscanos a Chiapas, esto debió ocurrir hasta 1577 , pues tal se deduce de un manuscrito del archivo del propio convento publicado por el obispo Orozco y Jiménez. 28 Poco tiempo después se debe haber comenzado a construir, pues el padre comisario Ponce, que estuvo alli en 1584, ya lo menciona: "Hay un convento de Santo Domingo y otro de nuestra orden que ha pocos años que se fundó, ibase haciendo de adobes y cubierto de paja, que aún no estaba acabado: su vocación es de San Antonio".

Como observa Orozco y Jiménez, la forma que correspondia a la iglesia - ya que el convento se encuentra arruinado- debe ser del siglo XVIII sin contar las modificaciones actuales: "Por lo que hace al convento se cree que desde el principio se hizo de la misma forma que ahora tiene, pero con las modificaciones que regularmente se hacen con el tienpo. En el siglo XVIII empiezan las reedificaciones, que si no fueron las primeras, nos revelan por lo menos que ya en el siglo XVII tenia la forma que dijimos, pues asi lo dan a entender las varias composiciones". 29

En su interior conserva esta iglesia algunas pinturas interesantes para la escuela chiapaneca, en especial si se tiene en consideración la pobreza de este arte que hay en aquella región. Tres llevan firma: un San Francisco, de Valladares, pintor guatemalteco, y otras dos, de Manuel de Santaella y de Eusebio Aguilar. Otras, igualmente importantes, existen anónimas.

Iglesia y tơrre del Carmen (antiguo Convento de la Encarnación).

Uno de los templos más ricos en escultura y más inportante por la construcción de la torre anexa, es el del Carmen, advocación que lo es de los primeros años de este siglo, ya que antiguamente fué la iglesia del convento de las monjas Concepcionistas de la Encarnación.

Pocos son los datos que poseemos de tan importante fábrica: El padre Ponce hacia 1584 no menciona este convento; pero si lo hace, en 1625,

28 Orozco y Jiménez. Ob. Cit. T. II. Päg, 137.

29 Orožo y Jiménez. Ob. Cit. T. II. Pág. 140. 
Tomás Gage: "un pobre convento de monjas, bien gravoso para la población"; también se le menciona en el citado mantuscrito publicado por el obispo Orozco y Jiménez 30 y posterior a 1767 : "Hay un convento de monjas del título de la Encarnación de N. Sor". Asi, pues, el convento debió fundarse al finalizar del siglo XVI o, más probablemente, al principiar el XVII, constando que hacia 1625 ya existía aunque con gran penuria.

El templo es de una nave cortada por un crucero de un solo brazo, 1o que origina una singular traza en forma de $\mathrm{L}$. Como todos los templos de aquella región, está techado con viguería en tijera. Escaso o nulo es el interés de sus portadas, pero en cambio la torre anexa a la iglesia es un monumento de importancia artística extraordinaria, Muy probablemente sea obra de la segunda mitad del XVII, época de intensa construcción religiosa en aquella región. El grandioso torreón sirve de campanario a la iglesia y en su parte inferior está calado por un vano qute probablemente sirvió de puerta de acceso al convento de monjas, a menos que desde un principio se le concibiera como pórtico de acceso a dos zonas de la ciudad, pues no sólo por su tradición mudéjar, sino por sus finalidades, recuerda una de las puertas de Segovia.

El interior del templo encierra un gran interés por conservar magníficas esculturas estofadas y policromadas de los siglos XVII y XVIII. Mencionaremos entre ellas un Cristo en la Cruz, muy probablemente de la escuela guatemalteca; otra la preciosa y muy fina Santa Ana y la Virgen niña, obra del siglo XVIII; $y$, por último, el San Sebastián, notable por la belleza y el realismo con que está tratado el desnudo humano, así como por la fuerza dramática de la actitud del Santo: esta escultura se podría relacionar con el San Sebastián de la Catedral de Guatemala, obra de Juan de Chávez, de 1737, siempre que encontramos en ésta menos amaneramiento y más dinámica, expresado todo con fuerza dramática superior.

Una casa plateresca de don Andrés de la Tobilla (?)

La residencia plateresca de San Cristóbal es otro de los más importantes monumentos artísticos de Chiapas. Hasta ahora sólo se mencionaba una casa plateresca del XVI, la del Adelantado Montejo en Mérida. Hoy podemos añadir la casa de San Cristóbal, que si no la aventaja en belleza

30 Orozco y Jiménez Ob. Cít. T. II. Pág. 18. 
- en riqueza decorativa, si encierra un enorne interés para la historia del estilo plateresco de nuano indígena en el México del siglo XVI.

I a portada de la casa es a dos cuerpos: consta a ambos lados de dos columnas superpuestas que se encuentran separadas del muro y descansando sobre la cornisa; los capiteles de la segunda columna rematan, a ambos lados, en sendas figuras de leones de basta, pero ingenua mano indigena; al centro y en lo alto del segundo cuerpo de la fachada - cuyo nuro todo es de piedra labrada en encasetonados-- se encuentra una pequeña ventana decórada en sus jambas y dintel con arabescos decorativos. Su época de edificación debe ser posterior a la segunda mitad del siglo XVI, no siendo improbable que se construyera contemporáneamente a la de Montejo en Mérida, es decir, hacia 1557.

E. padre Andrade alude vagamente a esta residencia mencionándola como Casa del Corregidor. Ignoramos de dónde tomaria este dato. Popularmente se le llama la Casa de la Sirena, pues en el ángulo que mira a la plaza se encuentra la figura de una sirena tallada en piedra, de enorme interés para las reminiscencias indigenas en el arte del siglo XVI. Otra tradición asigna la casa a don Andrés de la Tobilla: fue este personaje uno de los conquistadores de Chiapas, ya que figura como uno de los conpañeros de Mazariegos en 1527; más tarde se le encuentra en el cabildo de Ciudad Real y como su procurador ante la Audiencia de México; ignoramos si más adelante sería corregidor de la ciudad y si para entonces construyera la residencia. Infortmadamente para su identificación no podemos acudir al escudo de la fachada, pues éste fué destruido en sus campos; actualmente sólo resta el yelmo y plumas que enmarcan el escudo, estos últimos elementos por demás conuues. pero que si guardan analogías con el escudo de la familia 'Tobilla, según una genealogia manuscrita del obispo Orozco y Jiménez que se encuentra en el Museo Regional cle Chiapas. 


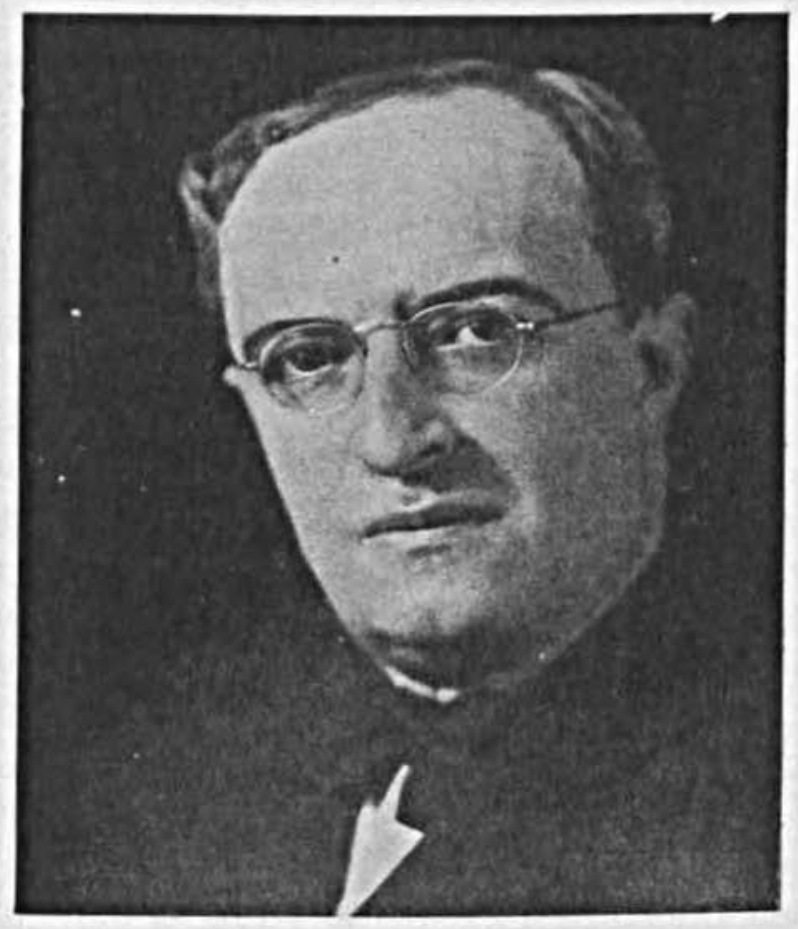

\section{FRANCISCO PEREZ SALAZAR}

\section{9-1941}

Escribo su nombre como él lo grababa al frente de sus libros: olvidando voluntariamente los des nobiliarios. Francisco Pérez Salazar ha muerto. Perdió Puebla a uno de sus más amorosos hijos y al historiador más consciente y serio de su arte. Ninguno tan honesto para investigar 
hasta el último rincón de la vida de los artistas, para comprobar delbidamente hasta el minimu de sus asertos, para expresar, dentro de sus posibilidades, cuanto habia que decir de la obra y del hombre. Desgraciadamente la urgencia de la vida y los odiosos menesteres cotidianos. inopidieron que Pérez Salazar realizase la obra a que tenía derecbo. Nos deja una breve Historia de la Pintura Colonial en Puebla, otra sobre el Cirabarlo en la misna ciuclad, sus estudios sobre Sigüenza y Góngora y algo más. A pesar de lo exiguo de los títulos, algunos son imprescindibles para la historia del arte en México, $y$ asi nadie podrá escribir sobre la pintura colonial si no tiene presente el trabajo de P'érez Salazar en sus dos ediciones: la primera publicada en 1923 en los Anales de la Sociedad Alzate y la segunda, que no llegó a circular, en nno de esos lilurotes que los gobernadores de los Fstados gustan de hacer para echarla de cultos de ve" en cuando. Ia edición fué destruída antes de salir por el gobernador que sucedió al que la iniciara y del importante trabajo, como de los otros documentos publicados en el misno libro por Pérez Salazar. sólo se conocen dos o tres ejemplares.

Iil Instituto de Investigaciones Listéticas rinde homenaje al desaparecido escritor y espera dar cina a uno de sus deseos que no pudo ver logrados: hacer una nueva edición de la Historia de la Pintura Colonial en Puebla, remiendo los nuevos materiales que el autor había allegado y otros de fuentes diversas. Y no es posible, porque sería un absurdo, dejar de rendir tributo igualmente al amigo, al que supo antes que nada ser bondadoso, al que tuvo siempre su biblioteca $y$ su archivo de fotografias abiertos a disposición de los estudiosos. Jil stipo, $y$ necesario es insistir en ello en estos tiempos en que está tan olvidado, poner la bondad por encima de todas las cosas. Supo ser bueno antes que nada, y por eso no deja sino una estela de recuerdos gratos. Su nombre lo conservará la Historia del Arte. 


\section{BIBLIOGRAFIA \\ $\mathrm{DE}$ \\ FRANCISCO PEREZ SALAZAR}

Algunos datos sobre la pintura en Puebla en la época Colonial.--En Memorias y Revistas de la Sociedad Cientifica "Anronio Alzate",-México, 1923,- - Tomo 41. Números 5 y 6 .

El Primer Marqués de Sierra Nevada.-Memorias de la Sociedad "Antonio Alzate". Talleres Gráficos de la Nación.-México. 1923.

I.a Furdación de la Ciudad de Puebla.-Sociedad Mexicana de Geografia y Estadistica. México. 1928.

Biografia del Lic. D. Pascual Almazán.-Sociedad Cientifica "Antonio Alzate".Imprenta de la Secretaria de Gobernación.-México. 1928.

Biografía de D. Carlos de Sigüenza y Góngora, seguida de varios documentos.-México. Antigua Imprenta de Murguia, 1928, 197 páginas. Edición de cien ejemplares numerados.

El grabado en la ciudad de Puebla de los Angeles.-Editorial Cultura.-Méxíco. 1933.

Las pinturas del Camatín de Ocotlán.-Imprenta Mundial.-México. 1937.

Los Impresores en Puebla en la Epoca Colonial.-Sobretiro de la Obra IV Centenario de la Imprenta en México, la Primeta en América. Conferencias sustentadas en su conmemoración. Asociación de Libreros de México.-México. MCMXXXIX.

Los Concursos Literarios de la Nueva España y el "Triumpho Parthenico". Revista de Literatura Mexicana. Octubre-diciembre 1940. México. 


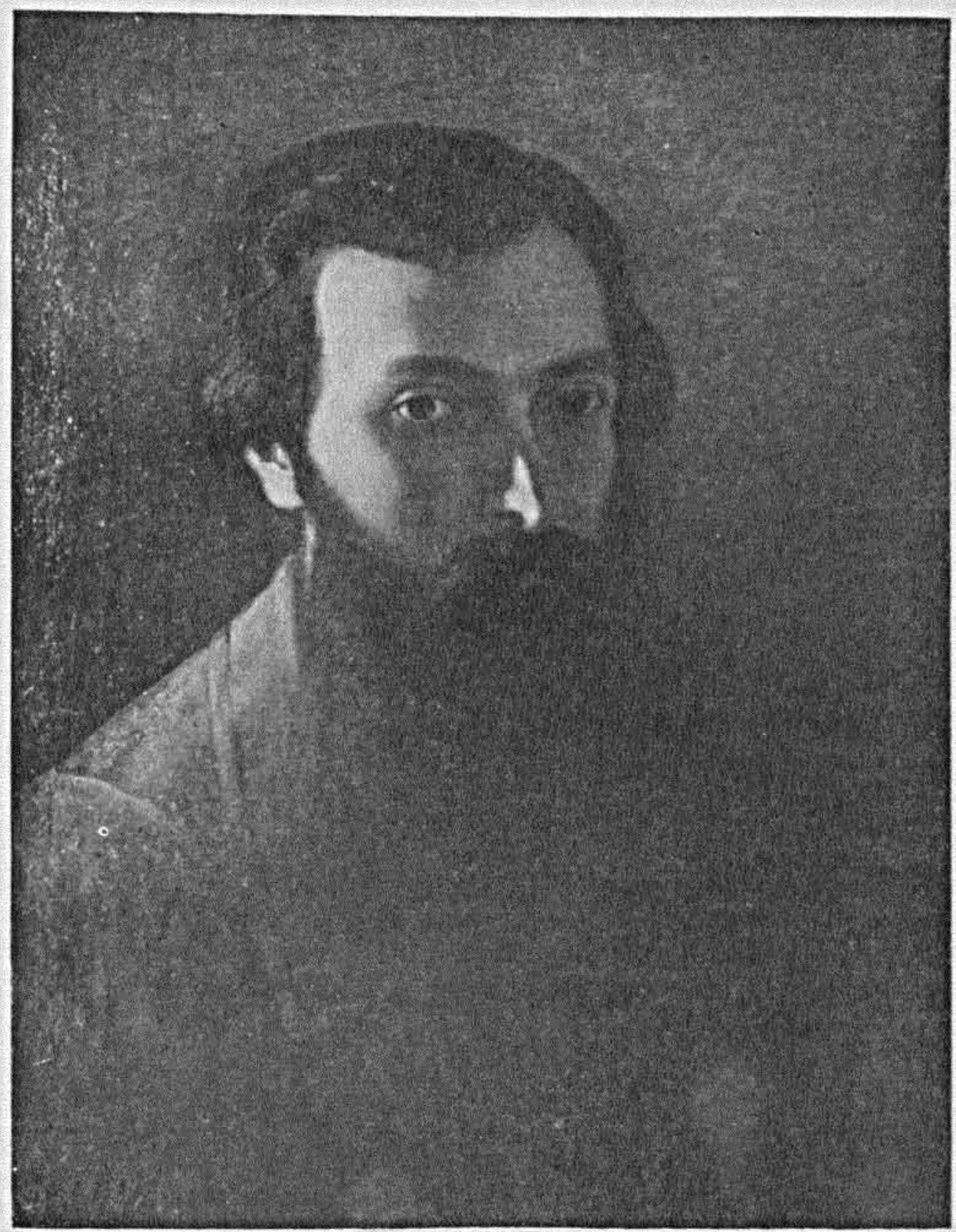

1. Autorretrato del pintor José Justo Montiel, 1863. (Foto Márquez.) 